\title{
The complete chloroplast genome sequence of strawberry (Fragaria $x$ ananassa Duch.) and comparison with related species of Rosaceae
}

\author{
Hui Cheng ${ }^{1}$, Jinfeng Li ${ }^{2}$, Hong Zhang ${ }^{1}$, Binhua Cai ${ }^{1}{ }^{\text {, }}$ Zhihong Gao ${ }^{1}$, Yushan Qiao ${ }^{\text {Corresp., }}{ }^{1}$, Lin Mi ${ }^{\text {Corresp. }} 2$ \\ 1 Laboratory of Fruit Tree Biotechnology, College of Horticulture, Nanjing Agricultural University, Nanjing, China \\ 2 Laboratory of Fruit Tree, Zhenjiang Institute of Agricultural Sciences in Hilly Area of Jiangsu, Jurong, China \\ Corresponding Authors: Yushan Qiao, Lin Mi \\ Email address: qiaoyushan@njau.edu.cn, jsrmn6217@sina.com
}

Compared with other members of the family Rosaceae, the chloroplast genomes of Fragaria species exhibit low variation, and this situation has limited phylogenetic analyses; thus, complete chloroplast genome sequencing of Fragaria species is needed. In this study, we sequenced the complete chloroplast genome of $F . \times$ ananassa 'Benihoppe' using the Illumina HiSeq 2500-PE150 platform and then performed a combination of de novo assembly and reference-guided mapping of contigs to generate complete chloroplast genome sequences. The chloroplast genome exhibits a typical quadripartite structure with a pair of inverted repeats (IRs, 25,936 bp) separated by large (LSC, 85,531 bp) and small (SSC, 18,146 bp) single-copy (SC) regions. The length of the $F . \times$ ananassa 'Benihoppe' chloroplast genome is $155,549 \mathrm{bp}$, representing the smallest Fragaria chloroplast genome observed to date. The genome encodes 112 unique genes, comprising 78 protein-coding genes, 30 tRNA genes and 4 rRNA genes. Comparative analysis of the overall nucleotide sequence identity among ten complete chloroplast genomes confirmed that for both coding and non-coding regions in Rosaceae, SC regions exhibit higher sequence variation than IRs. The Ka/Ks ratio of most genes was less than 1 , suggesting that most genes are under purifying selection. Moreover, the mVISTA results also showed a high degree of conservation in genome structure, gene order and gene content in Fragaria, particularly among three octoploid strawberries which were $F . \times$ ananassa 'Benihoppe', $F$. chiloensis (GP33) and F. virginiana (0477). However, when the sequences of the coding and noncoding regions of $F . \times$ ananassa 'Benihoppe' were compared in detail with those of $F$. chiloensis (GP33) and $F$. virginiana (0477), a number of SNPs and InDels were revealed by MEGA 7. Six non-coding regions (trnK-matK, trnS-trnG, atpF-atpH, trnC-petN, trnT-psbD and $t r n P-p s a J)$ with a percentage of variable sites greater than $1 \%$ and no less than five parsimony-informative sites were identified and may be useful for phylogenetic analysis of the genus Fragaria. 


\section{The complete chloroplast genome sequence of strawberry}

2 (Fragaria $\times$ ananassa Duch.) and comparison with related

\section{3 species of Rosaceae}

4 Hui Cheng ${ }^{1}$, Jinfeng $\mathrm{Li}^{2}$, Hong Zhang ${ }^{1}$, Binhua $\mathrm{Cai}^{1}$, Zhihong Gao ${ }^{1}$, Yushan Qiao ${ }^{1 *}$, Lin $\mathrm{Mi}^{2} *$

$5 \quad{ }^{1}$ Laboratory of Fruit Tree Biotechnology, College of Horticulture, Nanjing Agricultural

6 University, Nanjing210095, China

$7 \quad{ }^{2}$ Laboratory of Fruit Tree, Zhenjiang Institute of Agricultural Sciences in Hilly Area of Jiangsu,

8 Jurong212400, China

$9 \quad *$ Corresponding authors

10 Yushan Qiao, qiaoyushan@njau.edu.cn

11 Lin Mi, jsrmn6217@sina.com

12 ABSTRACT

13 Compared with other members of the family Rosaceae, the chloroplast genomes of Fragaria 14 species exhibit low variation, and this situation has limited phylogenetic analyses; thus, complete

15 chloroplast genome sequencing of Fragaria species is needed. In this study, we sequenced the complete chloroplast genome of $F . \times$ ananassa 'Benihoppe' using the Illumina HiSeq 2500PE150 platform and then performed a combination of de novo assembly and reference-guided mapping of contigs to generate complete chloroplast genome sequences. The chloroplast genome exhibits a typical quadripartite structure with a pair of inverted repeats (IRs, 25,936 bp) separated by large (LSC, 85,531 bp) and small (SSC, 18,146 bp) single-copy (SC) regions. The length of

21 the $F . \times$ ananassa 'Benihoppe' chloroplast genome is $155,549 \mathrm{bp}$, representing the smallest 
22 Fragaria chloroplast genome observed to date. The genome encodes 112 unique genes, 23 comprising 78 protein-coding genes, 30 tRNA genes and 4 rRNA genes. Comparative analysis of

24 the overall nucleotide sequence identity among ten complete chloroplast genomes confirmed that

25 for both coding and non-coding regions in Rosaceae, SC regions exhibit higher sequence variation than IRs. The $\mathrm{Ka} / \mathrm{Ks}$ ratio of most genes was less than 1 , suggesting that most genes are under purifying selection. Moreover, the mVISTA results also showed a high degree of conservation in genome structure, gene order and gene content in Fragaria, particularly among three octoploid strawberries which were $F . \times$ ananassa 'Benihoppe', $F$. chiloensis (GP33) and $F$. virginiana (O477). However, when the sequences of the coding and non-coding regions of $F$. $\times$ ananassa 'Benihoppe' were compared in detail with those of $F$. chiloensis (GP33) and $F$. virginiana (O477), a number of SNPs and InDels were revealed by MEGA 7. Six non-coding regions (trnK-matK, trnS-trnG, atpF-atpH, trnC-petN, trnT-psbD and trnP-psaJ) with a percentage of variable sites greater than $1 \%$ and no less than five parsimony-informative sites were identified and may be useful for phylogenetic analysis of the genus Fragaria.

37 The chloroplast, which is considered to have originated from free-living cyanobacteria through endosymbiosis, plays an essential role in photosynthesis and many biosynthetic activities

39 (Keeling, 2004). Most chloroplast genomes of angiosperms exhibit a highly conserved organization with a typical quadripartite structure that includes two copies of inverted repeats

41 (IRs), separated by large (LSC) and small (SSC) single-copy (SC) regions (Palmer, 1991; Jansen et al., 2005). In general, the chloroplast genomes of angiosperms encode 110-130 genes with a 
43 size range of 120-160 kb (Palmer, 1985). Variation in genome size can be attributed to IR

44 expansion/contraction or even loss (Ma et al., 2014; Zhang et al., 2014; Lei et al., 2016).

45 Although chloroplast DNA (cpDNA) is inherited maternally in most angiosperms, cpDNA

46 transmission in Medicago sativa is reported to be biparental or paternal (Smith, Brigham \&

47 Fulton, 1986; Schumann \& Hancock, 1989), and paternal inheritance has been demonstrated in

48 Actinidia chinensis (Testolin \& Cipriani, 1997). Compared with the nuclear genome, the

49 chloroplast genome is small, and the rate of nucleotide substitutions is so low that the chloroplast

50 genome is considered to be an ideal system for studies on phylogeny (Wei et al., 2005). In

51 addition, chloroplast transformation presents the advantages of producing high protein levels,

52 site-specific integration of transgenes, and a lack of posttranscriptional gene silencing, making it

53 an environmentally friendly strategy for plant genetic engineering (Daniell, Khan \& Allison,

54 2002; Bock, 2014).

55 The family Rosaceae includes approximately 3000 species from 90 genera distributed throughout the world, with particular enrichment in the North Temperate Zone (Potter et al., 2007), and many species of Rosaceae exhibit important economic value, such as common fruits, including apple (Malus), pear (Pyrus), peach (Prunus) and strawberry (Fragaria) as well as ornamentals, e.g., Rosa and Spiraea. The assembled nuclear genomes of Malus $\times$ domestica (Velasco et al., 2010), seven Fragaria species (Shulaev et al., 2011; Hirakawa et al., 2014; Tennessen et al., 2013), Prunus mume (Zhang et al., 2012), Pyrus bretschneideri (Wu et al., 2013), Prunus persica (Verde et al., 2013), and Rubus occidentalis (VanBuren et al., 2016) have been reported, providing valuable information for evolutionary classification. Nevertheless, due 
64

to apomixis, hybridization and assumed rapid radiation, the phylogenetic relationships among Rosaceae species have long been uncertain (Potter et al., 2007; Campbell et al., 2007; Lo \& Donoghue, 2012). With the rapid development of next-generation sequencing, researchers recently sequenced 125 new transcriptomic and genomic datasets and identified hundreds of nuclear genes to reconstruct a well-resolved Rosaceae phylogeny (Xiang et al., 2017). Moreover, 130 complete chloroplast genomes in Rosaceae have also been sequenced, and the phylogenetic relationships among members of this family have been thoroughly analyzed (Zhang et al., 2017).

The genus Fragaria belongs to subtribe Fragariinae within tribe Potentilleae of subfamily Rosoideae (Potter et al., 2007; Xiang et al., 2017) and is comprised of one cultivated (F. × ananassa) and 24 wild species (Staudt, 2009; Hummer, Nathewet \& Yanagi, 2009). Fragaria species exhibit natural variation in ploidy ranging from diploid to decaploid (Hummer Nathewet \& Yanagi, 2009; Hummer, 2012), although chloroplast DNA is unaffected by such changes in ploidy, which can complicate phylogenetic analyses (Palmer, 1986). Moreover, as haplotype analysis supports maternal inheritance of the chloroplast genome in Fragaria (Honjo et al., 2009; Davis et al., 2010), phylogenetic analyses of Fragaria have been attempted using chloroplast genome sequences (Harrison, Luby \& Furnier, 1997; Potter, Luby \& Harrison, 2000; Lin \& Davis, 2000; Njuguna et al., 2013; Govindarajulu et al., 2015). Although Fragaria exhibits limited variation in chloroplast sequences (Njuguna, 2010), comparative analyses of Fragaria using the entire chloroplast genome can provide comprehensive genetic information, for example, on InDels and nucleotide substitutions, which can be utilized as molecular markers and for diversity analyses (Cho et al., 2015). To date, seven complete chloroplast genomes of Fragaria 
85 have been released by National Centre for Biotechnology Information (NCBI, 86 https://www.ncbi.nlm.nih.gov/), for one accession each of the octoploids F. chiloensis (GP33, 87 PI612489) (GenBank: JN884816), and F. virginiana (O477, PI657873) (GenBank: JN884817);

diploid F. vesca ssp. vesca (Hawaii 4, PI551572) (GenBank: JF345175); three accessions of diploid F. vesca ssp. bracteata (MRD30, PI 664465; MRD102; LNF40) (GenBank: KC507755, KC507756, and KC507757); diploid F. pentaphylla (GenBank: KY434061), and a partial $130 \mathrm{~kb}$ chloroplast genome assembly of $F$. vesca ssp. americana (cp130096) as submitted GenBank (GU363535) (Davis et al., 2010). Thus, enrichment of complete chloroplast genomes is necessary to study evolution in Fragaria.

Cultivated strawberry $(F . \times$ ananassa Duch.) is one of the most economically important fruit crops in the world. It originated from accidental hybridization between $F$. virginiana and $F$. chiloensis in Europe during the early to mid-1700s, and systematic breeding using a small number of native and cultivated clones began in England and North America in the 1800s (Darrow, 1966). Wild strawberries have recently been employed to increase genetic diversity (Noguchi, 2011), though most modern strawberry cultivars are the progeny of $F . \times$ ananassa germplasm (Honjo et al., 2009; Hancock, 2008; Luby et al., 2008). F. × ananassa 'Benihoppe' (Registration no. 10371 in Japan, http://www.hinsyu.maff.go.jp/) was selected from Akihime $\times$ Sachinoka progenies in Shizuoka Prefecture, Japan, in 1994. This cultivar exhibits the characteristics of large size, rich flavor, firm texture and high yield (Takeuchi et al., 1999) and has become one of the main strawberry cultivars grown in China. The research of transgenic 'Benihoppe' strawberry via Agrobacterium-mediated to nuclear genome has been reported 
106 (Wang et al., 2014; Gu et al., 2015; Gu et al., 2017). However, the lack of a complete chloroplast

107 genome sequence is one of the major limitations restricting the development of chloroplast

108 genetic engineering.

109 Here, we report the first complete chloroplast genome of cultivated strawberry $(F . \times$ ananassa

110 'Benihoppe') based on next-generation sequencing methods (Illumina HiSeq 2500-PE150). In

111 addition to describing the characteristics of the chloroplast genome, we conducted comparative

112 analysis against nine other Rosaceae species, including Fragaria species in particular. The

113 generation of the complete chloroplast genome of $F . \times$ ananassa 'Benihoppe' is significant for

114 phylogenetic and evolutionary research within Fragaria and provides valuable data for

115 chloroplast genetic engineering and understanding molecular evolution.

116 MATERIALS AND METHODS

117 Plant material, DNA sequencing and genome assembly

118 Approximately $100 \mathrm{~g}$ of fresh young leaves of $F . \times$ ananassa 'Benihoppe' was collected from the

119 Zhenjiang Institute of Agricultural Sciences in a Hilly Area of Jiangsu, Jurong, China. The

voucher specimens were deposited in the laboratory of Fruit Tree Biotechnology of Nanjing

Agricultural University. Chloroplast DNA was extracted using the high-salt saline plus Percoll

gradient method of Vieira et al. (2014). A paired-end library was constructed from $50 \mathrm{ng}$ of

purified cpDNA according to the manufacturer's instructions (Illumina, San Diego, California,

USA). The library, which contained an insert size of $350 \mathrm{bp}$, was sequenced using the Illumina

HiSeq 2500-PE150 platform by Beijing Novogene Bioinformatics Technology Co., Ltd. (Beijing,

China). MITObim v1.8 (Hahn, Bachmann \& Chevreux, 2013) was utilized for de novo genome 
127 assembly, and the chloroplast genome reads were aligned to closely related cpDNA sequences 128 from $F$. vesca ssp. vesca Hawaii 4 (JF345175). Different k-mer sizes were tested, among which $12931 \mathrm{bp}$ produced the best results and was used to generate the final assembly in terms of the single 130 longest scaffold length. The junctions between SC and IR regions were verified through 131 polymerase chain reaction (PCR) amplification using sequence-specific primers (File S1). The PCR products were sequenced via Sanger sequencing.

\section{Genome annotation and codon usage}

The Dual Organellar GenoMe Annotator (DOGMA; http://dogma.ccbb.utexas.edu/, Wyman,

Jansen \& Boore, 2004) was employed to annotate the $F$. × ananassa 'Benihoppe' chloroplast

genome. The initial annotations and putative start, stop, and intron positions were checked

manually based on comparison with homologous genes in other Fragaria chloroplast genomes

available in the GenBank database. Additionally, tRNA genes were identified using tRNAscan-

SE 1.21 (http://lowelab.ucsc.edu/tRNAscan-SE/; Schattner, Brooks \& Lowe, 2005) and

ARAGORN (Laslett \& Canback, 2004). A circular chloroplast genome map of F. × ananassa

'Benihoppe' was constructed using the online tool OGDRAW (http://ogdraw.mpimp-

golm.mpg.de; Lohse, Drechsel \& Bock, 2007). GC content, codon usage and relative

synonymous codon usage (RSCU) were analyzed with MEGA 7 software (Kumar et al., 2008).

\section{Repeat structure and simple sequence repeats (SSRs)}

145 The sizes and locations of forward, reverse, palindromic and complementary repeats were determined with the REPuter program (Kurtz et al., 2001). The minimum identity and size of the 
148 chloroplast genome were detected using MISA (Thiel et al., 2003) with the following parameters:

149 minimum SSR motif length of $10 \mathrm{bp}$ and repeat lengths of mono-10, di-5, tri-4, tetra-3, penta-3

150 and hexa-3.

\section{Comparison with other Rosaceae chloroplast genomes}

152

153

154

155

156

157

158

159

160

161

162

163

164

165

166

167

One species was selected from each of the four most important fruit tree or ornamental species

(Malus Mill., Pyrus L., Prunus L., and Rosa L.) of Rosaceae and from the genus Fragaria, including $F$. chiloensis (GP33), F. virginiana (O477), F. vesca ssp. vesca (Hawaii 4), F. vesca ssp. bracteata (MRD30) and $F$. pentaphylla (KY434061). The complete chloroplast genome of $F$. $\times$ ananassa 'Benihoppe' was employed as a reference and was compared with the chloroplast genomes of the nine other species using mVISTA software in the Shuffle-LAGAN mode (Frazer et al., 2004).

\section{Nucleotide substitution in coding regions}

All 78 functional protein-coding genes were extracted from the six Fragaria species (Rosoideae), Rosa roxburghii (Rosoideae) (KX768420) and Prunus persica 'Nemared' (Amygdaloideae) (HQ336405), and 77 protein-coding genes from Malus prunifolia (MPRUN20160302) (Amygdaloideae) (KU851961) and Pryus pyrifolia 'Hosui' (Amygdaloideae) (AP012207) were employed because the $p s b L$ gene was not annotated. Each exon was aligned with those of $F$. $\times$ ananassa 'Benihoppe' using ClustalX v2.1 (Thompson et al., 1997). The alignment file was then analyzed with DnaSP v5 (Librado \& Rozas, 2009) to calculate synonymous (Ks) and nonsynonymous $(\mathrm{Ka})$ substitution rates. 
168

169

170

171

172

173

174

175

176

177

178

179

180

181

182

183

184

185

186

187

188

\section{cpDNA marker identification in Fragaria}

The seven complete chloroplast genomes of Fragaria species that have been released by NCBI (as above) as well as two nearly complete chloroplast genomes which were $F$. mandshurica (fc199s6) (KC507760) and F. iinumae (fc199s5) (KC507759) and the chloroplast genome of cultivar 'Benihoppe' were used to identify rapidly evolving molecular markers that may be employed for phylogenetic analysis of Fragaria. As the coding regions are highly conserved, only fragments from non-coding regions were considered. Homologous regions were aligned using MEGA 7 and adjusted manually where necessary. Then, the percentage of variable sites for each region was calculated. The proportion of mutation events $=(\mathrm{NS} / \mathrm{L}) \times 100$, where $\mathrm{NS}=$ number of nucleotide substitutions, and $\mathrm{L}=$ aligned sequence length ( $\mathrm{Li}$ et al., 2013). Because parsimony-informative sites (PIS) are commonly used in phylogenetic analyses, the number of PIS was calculated as well.

To examine the phylogenetic applications of rapidly evolving molecular markers, the maximum parsimony (MP) method was employed to construct phylogenetic trees using MEGA 7 with the following parameters: gaps in the alignment treated as missing, 1000 replicates for bootstrap support, and tree bisection-reconnection (TBR) branch swapping.

\section{RESULTS AND DISCUSSION}

\section{Chloroplast genome assembly, organization, and gene content}

In total, $276 \mathrm{Mb}$ of $150-\mathrm{bp}$ raw paired-end reads was retrieved and trimmed, and $241 \mathrm{Mb}$ of high-quality short reads was finally employed to assemble the chloroplast genome, using a combination of the MITObim v1.8 de novo assembly and reference-guided (GenBank: JF345175) 
189 190

mapping of contigs to generate complete chloroplast genome sequences. Finally, the generated data were assembled into the single longest scaffold spanning the $F . \times$ ananassa 'Benihoppe' chloroplast genome. To validate the assembly, four junctions between SC and IR regions were confirmed through PCR amplification and Sanger sequencing. No mismatches or InDels were observed between the Sanger sequencing and the assembled genome, which verified the correctness of our genome sequencing and assembly results.

The $F$. $\times$ ananassa 'Benihoppe' chloroplast genome is a typical circular double-stranded DNA molecule with a quadripartite structure; it is $155,549 \mathrm{bp}$ in size and consists of IR (25,936 bp) regions separated by $\operatorname{LSC}(85,531 \mathrm{bp})$ and $\operatorname{SSC}(18,146 \mathrm{bp})$ regions (Fig. 1, Table 1). The GC content of the chloroplast genome is $37.23 \%$ (Table 1), and the GC contents of the LSC and SSC regions $(35.12 \%$ and $31.14 \%)$ are lower than those of the IR regions $(42.85 \%)$. The high GC contents in the IR regions are mainly due to the high GC contents of the four ribosomal RNA (rRNA) genes (55.43\%) which is similar to most of other plants cp genomes (Wang, Shi \& Gao, 2013; Shen et al., 2016; Kong \& Yang, 2017).

There are 130 genes in the chloroplast genome of $F . \times$ ananassa 'Benihoppe', 112 of which are unique, including 78 protein-coding genes, 30 tRNA genes and 4 rRNA genes. The genes that are repeated in IRs comprise seven protein-coding genes, seven tRNA genes, and four rRNA genes (Fig. 1, Table 2). Among these genes, a single intron was detected in 15 genes (9 proteincoding genes and 6 tRNA genes), while 2 genes ( $y c f 3$ and $\operatorname{clp} P$ ) were found exhibit two introns each (File S2). The trnK-UUU gene harbors the largest intron (2,497 bp), which contains the matK gene, whereas the intron of trnL-UAA is smallest (422 bp). Two genes with internal stop 
210

211

212

213

214 215

216

217

218

219

220

221

222

223

224

225

226

227

228

229

230

codons (ycf15 and $y c f 68)$ and one without a stop codon (infA) were annotated as pseudogenes.

Absence or pseudogenization of these three genes has also been reported in other Rosaceae species, such as Eriobotrya japonica (Shen et al., 2016) and Prinsepia utilis (Wang, Shi \& Gao, 2013). The rps 12 gene is a trans-spliced gene with a $5^{\prime}$ exon located in an LSC region and two 3' exons located in IR regions. The complete chloroplast genome with gene annotations has been deposited in the NCBI GenBank database (accession number: KY358226).

Overall, 22,709 codons encoding 78 protein-coding genes were identified in the complete chloroplast genome and classified according to codon usage (File S3), among which 2,405 (10.59\%) encode leucine (the most abundant amino acid), and 252 (1.11\%) encode cysteine (the least abundant amino acid). RSCU analysis showed A/T contents of $53.89 \%, 61.84 \%$ and $70.17 \%$ at the first, second and third codon positions, respectively. This pattern of higher $\mathrm{A} / \mathrm{T}$ bias at the third codon position is common in the chloroplast genomes of land plants (Morton, 1998; Gurusamy \& Seonjoo, 2016).

\section{Repeat structure and SSR loci}

A total of 39 repeat structures with a minimal length of $30 \mathrm{bp}$ and minimal identity of $90 \%$ were found (File S4), including 14, 6, 2 and 17 forward, reverse, complementary, and palindromic structures, respectively. Among these structures, the longest is $67 \mathrm{bp}$ and is located between trnM-CAU and atpE. Most of the repeat structures are located in intergenic regions (65.4\%), while fewer than half are located in coding genes $(21.8 \%$; $n d h A, y c f 2, p s a A, p s a B, \operatorname{trn} S-G G A$, psbJ, trnG-UCC and trnG-GCC) or introns (12.8\%; ycf3, ndhB and $c l p P)$.

Simple sequence repeats (SSRs) in chloroplast genomes have become valuable molecular 
231

232

233

234

235

236

237

238

239

240

241

242

243

244

245

246

247

248

249

250

251

markers because of their high degree of variation within an individual species, which is useful

for linkage map construction and plant breeding (Powell et al., 1995; Xue, Wang \& Zhou, 2012).

In the $F . \times$ ananassa 'Benihoppe' chloroplast genome, 61 SSR loci with a length of at least 10

bp were detected, among which $38(62.3 \%)$ are mononucleotide repeats; $16(26.2 \%)$ are direpeats; $3(4.9 \%)$ are tri-repeats; and 4 are (6.6\%) tetra-repeats. No pentanucleotides or

hexanucleotides were found. Most of the observed mononucleotide repeat sequences consist of A/T motifs, whereas only one is composed of a G/C motif. Similarly, 93.75\% of the dinucleotide repeat sequences consist of AT/TA motifs. The results showed that the SSRs exhibit a strong AT bias, which is consistent with other studies (Lei et al., 2016; Kuang et al., 2011). Among the 61 SSR loci, 44 are located in intergenic regions, 8 in introns, and 9 in coding regions of genes (Table 3).

\section{Comparison with other chloroplast genomes from Rosaceae}

Nine chloroplast genomes representing five genera in Rosaceae were compared with that of $F$. $\times$ ananassa 'Benihoppe' (Table 1). The length of the Fragaria chloroplast genomes ranges from 155,549 to $155,691 \mathrm{bp}$, with $F$. vesca ssp. vesca (Hawaii 4) exhibiting the largest chloroplast genome and $F . \times$ ananassa 'Benihoppe' the smallest. The length of the LSC regions shows greater variation, ranging from 85,531 to $85,605 \mathrm{bp}$, with $F$. vesca ssp. vesca (Hawaii 4) exhibiting the longest, followed by $F$. virginiana (O477), while $F$. $\times$ ananassa 'Benihoppe' harbors the shortest (Table 1). However, the IR regions of diploid strawberries are longer than those of three octoploid strawberries. F. pentaphylla (KY434061) exhibits the shortest SSC regions. Furthermore, the size of the $F . \times$ ananassa 'Benihoppe' chloroplast genome is smaller 
252 than those of the other four species in Rosaceae, being approximately $4.5 \mathrm{~kb}, 4.4 \mathrm{~kb}, 2.2 \mathrm{~kb}$ and

$2531.2 \mathrm{~kb}$ smaller than those of M. prunifolia (MPRUN20160302), P. pyrifolia 'Hosui', P. persica

254 'Nemared', and $R$. roxburghii (KX768420), respectively. The differences in genome size can

255 largely be attributed to variation in the length of SSC and IR regions (Table 1).

256 The results also revealed that the gene content and gene order of $F . \times$ ananassa 'Benihoppe'

257 are identical to those of the five previously reported the genus Fragaria chloroplast genomes.

258 Interestingly, the loss of a group II intron of the atpF gene, as observed in Fragaria (Table 2),

259 has previously been reported for Malpighiales (Daniell et al., 2008) and R. roxburghii

260 (KX768420). However, the numbers of unique genes found in the $F . \times$ ananassa 'Benihoppe', $R$.

261 roxburghii (KX768420), M. prunifolia (MPRUN20160302), P. pyrifolia 'Hosui', and P. persica

262 'Nemared' chloroplast genomes were 112, 114, 111, 111 and 112, respectively, due to the

263 absence of the psbL gene in M. prunifolia (MPRUN20160302) and P. pyrifolia 'Hosui', the

264 absence of the $\operatorname{trn} G-G C C$ gene in $R$. roxburghii (KX768420), and the presence of three genes,

infA, trnP-GGG and trnM-CAU, only in $R$. roxburghii (KX768420). The GC content among the

ten species was similar, ranging from 36.56 to $37.25 \%$, with the seven Rosoideae species all

exhibiting a high GC content, of approximately $37.2 \%$ (Table 1).

The mVISTA program was employed to analyze the overall sequence identity among all ten

Rosaceae members at the chloroplast genome level, using the annotation for $F . \times$ ananassa

'Benihoppe' as a reference (Fig. 2). The results showed high similarity among the Fragaria 
273 chloroplast genome was most similar to that of $R$. roxburghii (KX768420) and most divergent

274 from that of $P$. persica 'Nemared'. Overall, the results revealed SC regions to be more divergent

275 than IR regions, with higher divergence being observed in non-coding regions than in coding

276 regions, which is a common phenomenon in the chloroplast genomes of angiosperms (Yao et al.,

277 2015; Ni et al., 2016; Asaf et al., 2016). The coding regions with marked differences include the

$278 y c f 1$, matK and $p s a I$ genes. The highest divergence in non-coding regions was found for rps 16-

$279 \operatorname{trn} Q$, pet $N-p s b M, n d h C$-trnV, petA-psbL and $r p l 32-c c s A$. These results are similar to those of

other analyses performed in Rosaceae (Wang, Shi \& Gao, 2013; Shen et al., 2016), suggesting

that these regions evolve rapidly in Rosaceae.

\section{IR contraction and expansion}

In general, IR regions are considered to be the most conserved regions in the chloroplast genome.

Nevertheless, expansion and contraction of the border region between SC and IR regions are

common during evolution and contribute to variation in chloroplast genome length (Wang et al.,

2008; Li et al., 2013). Thus, the positions of LSC/IRA/SSC/IRB borders and the adjacent genes

in the ten Rosaceae chloroplast genomes were aligned (Fig. 3). The SSC/IRB boundary of $F$. $\times$

ananassa 'Benihoppe' is consistent with those of the other Fragaria species. All of the genomes

except for those of $F$. vesca ssp. vesca (Hawaii 4) and F. pentaphylla (KY434061) exhibit

IRA/SSC boundaries of the same length, and due to contraction of the IR region at the IRB/LSC species. 
293 Compared with those of other Rosaceae species, the rps 19 genes of Fragaria species and $R$.

294 roxburghii $(\mathrm{KX} 768420)$ are shifted to an LSC region with a 12-21 bp gap. However, the $\operatorname{rps} 19$

295 genes of M. prunifolia (MPRUN20160302), P. pyrifolia 'Hosui' and P. persica 'Nemared'

296 extend from the LSC to the IRA region, showing variability of 120-182 bp, resulting in the

297 presence of an rps19 pseudogene of the same length in IRB. The SSC/IRB boundary extends to

298 the $y c f 1$ coding region, ranging from $1051 \mathrm{bp}$ (P. persica 'Nemared') to 1106 bp (R. roxburghii,

KX768420), leading to a nonfunctional $y c f 1$ gene in IRA. The $n d h F$ gene is located entirely in

the SSC region in Rosoideae species but varies in distance from the IRA/SSC border. However,

in M. prunifolia (MPRUN20160302), P. pyrifolia 'Hosui', and P. persica 'Nemared', part of the

$n d h F$ gene is located in IRA. In general, the position of the $\operatorname{trn} H$ gene in the chloroplast genome

is quite conserved between monocot and dicot species. In monocots, the trnH gene is located in

the IR region, whereas it is located in the LSC region in dicots (Asano et al., 2004). In all of the

analyzed genomes, the $\operatorname{trn} H$ gene is located in the LSC region, although its distance from the

IRB/LSC junction ranges from 0 to $101 \mathrm{bp}$. Overall, a similar pattern of expansion and

contraction of IR/SC regions was observed among the Fragaria species and $R$. roxburghii

(KX768420), differing from M. prunifolia (MPRUN20160302), $P$. pyrifolia 'Hosui' and $P$.

persica 'Nemared' (Fig. 3).

310 Selection pressure on the $\boldsymbol{F} . \times$ ananassa 'Benihoppe' chloroplast

genome

$312 \mathrm{The} \mathrm{Ka} / \mathrm{Ks}$ ratio was calculated for 78 protein-coding genes in all nine chloroplast genomes, with 313 a value of 0 indicating neutral selection. The $\mathrm{Ka} / \mathrm{Ks}$ ratio of the Fragaria chloroplast genomes 
314 was typically calculated to be 0 , except for six genes in $F$. vesca ssp. vesca (Hawaii 4) (rpoC2, $315 n d h D, n d h F, p s b B, y c f 1$ and $y c f 4)$, three genes in $F$. vesca ssp. bracteata (MRD30) (ndhF, ycfl, 316 and $y c f 4)$ and thirteen genes in $F$. pentaphylla (KY434061) (rpoC1, rpoC2, atpB, atpH, ndhA, $317 n d h D, n d h F, n d h H, p e t A, p s b B, r b c L, y c f 1$ and $y c f 4)$ (File S5).

318 Among the protein-coding genes in the chloroplast genomes of the other Rosaceae species, the $319 \mathrm{Ka} / \mathrm{Ks}$ ratio was observed to be highest in genes within the SSC regions (Table 4). In the comparison of Fragaria with Rosa and Malus, the lowest Ka/Ks ratio was found in the IR region.

However, in the comparison of Pyrus and Prunus, the LSC region showed the lowest Ka/Ks ratio

(Fig. 4, Table 4). The lowest $\mathrm{Ka} / \mathrm{Ks}$ ratio was observed for genes encoding subunits of ATP synthase, subunits of the cytochrome b/f complex, subunits of photosystem II and the large subunit of RuBisCO (File S5). With the exception of the $r p l 16$ gene of Rosa, the Ka/Ks ratio of all genes was found to be less than 1, suggesting purifying selection on these genes (Fig. 4).

\section{Variation in chloroplast DNA in three octoploid strawberries}

The complete chloroplast genomes were found to be most similar among the three octoploid strawberries. However, when the sequences of the coding and non-coding regions of $F$. $\times$ ananassa 'Benihoppe' were compared in detail with those of $F$. chiloensis (GP33) and $F$. virginiana (O477), a number of SNPs and InDels were revealed (Table 5).

In total, 35 SNPs (26 transversions and 9 transitions) were identified between the complete $F$.

$\times$ ananassa 'Benihoppe' and F. chiloensis (GP33) chloroplast genomes, which were found in all types of regions (23 in LSC, 9 in SSC and 3 in IR regions). Two SNPs in the $r p o B$ and $n d h F$ genes represent synonymous changes, whereas the other six SNPs in four other genes $(a c c D$, 
$n d h H, y c f 1$ and $y c f 4$ ) are nonsynonymous and may alter the encoded protein's primary structure.

336 Overall, 18 InDels between 1 and 19 bp in length were found, including 15 within LSC regions.

337 In contrast, 23 SNPs (17 transversions and 6 transitions) were identified between the $F$. $\times$

338 ananassa 'Benihoppe' and F. virginiana (O477) chloroplast genomes, among which 21 are

339 located in LSC and 2 in SSC regions, while none were found in IR regions. Three

340 nonsynonymous SNPs were found in the petB, $y c f 1$ and $y c f 4$ genes, while three synonymous

341 SNPs were found in $r p s 8, r p o B$, and $p s b A$. Eight InDels were observed (5 insertions and 3

342 deletions), all but one of which is located within the LSC region.

343 Regardless of location or subspecies, all F. virginiana individuals share the same SNPs in two 344 genes, petD $(\mathrm{G})$ and $n d h F(\mathrm{~A})$, differing from $F$. chiloensis at these positions (petD: A; $n d h F$ : G)

345 (Salamone et al., 2013). Furthermore, Honjo et al. (2009) examined two non-coding regions and

346 concluded that cultivar 'Benihoppe' exhibits haplotype $\mathrm{V}$, which is consistent with its female

347 parent Akihime. Based on our SNP analysis, two genes (petD and $n d h F$ ) and two non-coding 348 regions (trnL-trnF and trnR-rrn5) are consistent with $F$. virginiana and different from $F$. 349 chiloensis. Our results are in accordance with previous studies (Salamone et al., 2013; Honjo et 350 al., 2009) and indicate that the sequence identity between $F$. $\times$ ananassa 'Benihoppe' and $F$. virginiana $(\mathrm{O} 477)$ at the chloroplast level is higher than between $F . \times$ ananassa 'Benihoppe' and

F. chiloensis (GP33).

\section{3 cpDNA markers and sequence polymorphisms in Fragaria}

354 Non-coding regions (introns and intergenic spacers), harboring more sequence divergence, are 355 not subject to the functional constraints that could extend the utility of a molecule at lower 
356

357

358

359

360

361

362

363

364

365

366

367

368

369

370

371

372

373

374

375

376

taxonomic levels (Small et al., 1998; Shaw et al., 2007). At least six non-coding regions of cpDNA were previously examined in phylogenetic and ancestry studies of Fragaria. Universal primers targeting the trnL-trnF region (Taberlet et al., 1991) were used in previous studies to investigate 14 species of Fragaria (Potter, Luby \& Harrison, 2000) and 8 diploid species from this genus (Sargent, 2005). The trnT-trnL, atpB-rbcL, psbA-trnH, psbJ-psbF and rps18-rpl20 regions have also been employed to detect sequence polymorphisms in Fragaria (Sargent, 2005; Lin \& Davis, 2000). However, due to the small group of taxa sampled or a low level of sequence variation in these regions, the phylogenetic resolution within Fragaria has been limited (Rousseau-Gueutin et al., 2009).

To examine which regions might be applied for Fragaria phylogenetic analysis, all of the noncoding regions among ten Fragaria chloroplast genomes were aligned, and sequence divergence was calculated (Fig. 5). The results showed that $n d h E-n d h G$ exhibits the highest rate of variation (7\%), while atpF-atpH and trnT-psbD exhibit the most PIS. However, only the 6 intergenic regions (trnK-matK, trnS -trnG, atpF-atpH, trnC-petN, trnT-psbD, and trnP-psaJ) display a percentage of variable sites higher than $1 \%$ and more than five PIS (Fig. 5), indicating the low variation of chloroplast genomes in Fragaria. Interestingly, these intergenic regions are all located in the LSC region, whose sequence has been noted to be less conserved in those of IR and SSC regions and has consequently been used for phylogenetic analysis at low taxonomic levels (Njuguna, 2010).

To examine the phylogenetic applications of the six fast-evolving DNA regions, an MP tree was constructed for each molecular marker from the ten Fragaria species (File S6). The results 
377 revealed that none of each region was efficient in resolving the relationships among the

378 examined samples. However, the combined regions strongly supported F. iinumae (fc199s5) and

$379 F$. pentaphylla (KY434061) had the closest phylogenetic relationship. Furthermore, our results

380 showed $F$. vesca ssp. vesca (Hawaii 4) was closer to F. vesca ssp. bracteata (LNF40), which was

381 similar to Govindarajulu et al. (2015). The STEMhy and PhyloNet results showed a greater

382 contribution of $F$. iinumae than $F$. vesca to the ancestry of the octoploids (Kamneva et al., 2017).

383 Vining et al. (2017) used POLIMAPS to resolve $F . \times$ ananassa chromosomal regions derived

384 from diploid ancestor $F$. vesca. Our results couldn't infer which one was the ancestor of $F$. $\times$

385 ananassa 'Benihoppe' (KY358226) at present. Further studies with a broad sampling scheme

386 need to be conducted to test the efficiency of these six identified regions in phylogenetic analysis

387 of Fragaria.

388 CONCLUSIONS

389 This study provides the first report of the complete chloroplast genome sequence of $F$. $\times$

390 ananassa 'Benihoppe'. Comparison with nine Rosaceae species revealed higher sequence

391 variation in SC regions compared with IR regions in both coding and non-coding regions, and

392 the gene order, gene content and genome structure were found to be similar to those of other

393 sequenced Fragaria species, especially F. virginiana (O477) and F. chiloensis (GP33),

394 demonstrating low variation among Fragaria chloroplast genomes. However, IR contraction is

395 observed in $F . \times$ ananassa 'Benihoppe', and several SNPs and InDels identified among three

396 octoploid strawberries can be utilized for diversity analyses. Six non-coding regions (trnK-matK, 
398

399

400

401

402

403

404

405

406

407

408

409

410

411

412

413

414

415

416

417

418

analysis of the genus Fragaria. The chloroplast genome of $F . \times$ ananassa 'Benihoppe' may also provide important information for research related to the chloroplast transgenic engineering of cultivated strawberry.

\section{REFERENCES}

Asaf S, Khan AL, Khan AR, Waqas M, Kang SM, Khan MA, Lee SM, Lee IJ. 2016. Complete chloroplast genome of Nicotiana otophora and its comparison with related species. Frontiers in Plant Science 7: 843 DOI 10.3389/fpls.2016.00843.

Asano T, Tsudzuki T, Takahashi S, Shimada H, Kadowaki K. 2004. Complete nucleotide sequence of the sugarcane (Saccharum officinarum) chloroplast genome: a comparative analysis of four monocot chloroplast genomes. DNA Research 11: 93-99 DOI 10.1093/dnares/11.2.93.

Bai LJ, Ye YT, Chen Q, Tang HR. 2017. The complete chloroplast genome sequence of the white strawberry Fragaria pentaphylla. Conservation Genetics Resources DOI 10.1007/s12686-017-0713-5.

Bao L, Li K, Liu Z, Han M, Zhang D. 2016. Characterization of the complete chloroplast genome of the Chinese crabapple Malus prunifolia (Rosales: Rosaceae: Maloideae). Conservation Genetics Resources 8: 227-229 DOI 10.1007/s12686-016-0540-0.

Bock R. 2014. Engineering chloroplasts for high-level foreign protein expression. Humana Press 1132: 93-106 DOI 10.1007/978-1-62703-995-6_5.

Campbell CS, Evans RC, Morgan DR, Dickinson TA, Arsenault MP. 2007. Phylogeny of subtribe Pyrinae (formerly the Maloideae, Rosaceae): Limited resolution of a complex 
419

420

421

422

423

424

425

426

427

428

429

430

431

432

433

434

435

436

437

438

439

evolutionary history. Plant Systematics \& Evolution 266: 119-145 DOI 10.1007/s00606007-0545-y.

Cho KS, Yun BK, Yoon YH, Hong SY, Mekapogu M, Kim KH, Yang TJ. 2015. Complete chloroplast genome sequence of tartary buckwheat (Fagopyrum tataricum) and comparative analysis with common buckwheat (F. esculentum). PLOS ONE 10: e0125332 DOI 10.1371/journal.pone.0125332.

Daniell H, Khan MS, Allison L. 2002. Milestones in chloroplast genetic engineering: an environmentally friendly era in biotechnology. Trends in Plant Science 7: 84-91.

Daniell H, Wurdack KJ, Kanagaraj A, Lee SB, Saski C, Jansen RK. 2008. The complete nucleotide sequence of the cassava (Manihot esculenta) chloroplast genome and the evolution of $a t p F$ in Malpighiales: RNA editing and multiple losses of a group II intron. Tagtheoretical \& Applied Geneticstheoretische Und Angewandte Genetik 116: 723-737 DOI 10.1007/s00122-007-0706-y.

Darrow GM. 1966. The strawberry. History, breeding and physiology. Holt, Rinehart and Winston, New York, USA.

Davis TM, Shields ME, Reinhard AE, Reavey PA, Lin J, Zhang H, Mahoney LL, Bassil NV, Martin R. 2010. Chloroplast DNA inheritance, ancestry, and sequencing in Fragaria. Acta Horticulturae 859: 221-228.

Frazer KA, Pachter L, Poliakov A, Rubin EM, Dubchak I. 2004. VISTA: computational tools for comparative genomics. Nucleic Acids Research 32: W273-W279 DOI 10.1093/nar/gkh458. 
440 Govindarajulu R, Parks M, Tennessen JA, Liston A, Ashman TL. 2015. Comparison of

441

442

443

444

445

446

447

448

449

450

451

452

453

454

455

456

457

458

459

460

nuclear, plastid, and mitochondrial phylogenies and the origin of wild octoploid strawberry species. American Journal of Botany 102: 544-554 DOI 10.3732/ajb.1500026.

Gu X, Chen Y, Gao Z, Qiao Y, Wang X. 2015. Transcription factors and anthocyanin genes related to low-temperature tolerance in $r d 29 A$ : RdreB1BI transgenic strawberry. Plant Physiology and Biochemistry 89: 31-43 DOI 10.1016/j.plaphy.2015.02.004.

Gu X, Gao Z, Yan Y, Wang X, Qiao Y, Chen Y. 2017. RdreB1BI enhances drought tolerance by activating AQP-related genes in transgenic strawberry. Plant Physiology and Biochemistry 119: 33-42 DOI 10.1016/j.plaphy.2017.08.013.

Gurusamy R, Seonjoo P. 2016. The complete chloroplast genome sequence of Ampelopsis: gene organization, comparative analysis, and phylogenetic relationships to other angiosperms. Frontiers in Plant Science 7: 341 DOI 10.3389/fpls.2016.00341.

Hahn C, Bachmann L, Chevreux B. 2013. Reconstructing mitochondrial genomes directly from genomic next-generation sequencing reads--a baiting and iterative mapping approach. Nucleic Acids Research 41: e129 DOI 10.1093/nar/gkt371.

Hancock JF. 2008. Strawberries. Temperate Fruit Crops in Warm Climates 16: 393-438.

Harrison RE, Luby JJ, Furnier GR. 1997. Chloroplast DNA restriction fragment variation among strawberry (Fragaria spp.) taxa. Journal of the American Society for Horticultural Science 122: 63-68.

Hirakawa H, Shirasawa K, Kosugi S, Tashiro K, Nakayama S, Yamada M, Kohara M, Watanabe A, Kishida Y, Fujishiro T, Tsuruoka H, Minami C, Sasamoto S, Kato M, 
461

462

463

464

465

466

467

468

469

470

471

472

473

474

475

476

477

478

479

480

481

Nanri K, Komaki A, Yanagi T, Guoxin Q, Maeda F, Ishikawa M, Kuhara S, Sato S, Tabata S, Isobe SN. 2014. Dissection of the octoploid strawberry genome by deep sequencing of the genomes of Fragaria species. DNA Research 21: 169-181 DOI 10.1093/dnares/dst049.

Honjo M, Kataoka S, Yui S, Morishita M, Kunihisa M, Yano T, Hamano M, Yamazaki H. 2009. Maternal lineages of the cultivated strawberry, Fragaria $\times$ ananassa, revealed by chloroplast DNA variation. HortScience 44: 1562-1565.

Hummer KE, Nathewet P, Yanagi T. 2009. Decaploidy in Fragaria iturupensis (Rosaceae). American Journal of Botany 96: 713-716 DOI 10.3732/ajb.0800285.

Hummer KE. 2012. A new species of Fragaria (Rosaceae) from Oregon. Journal of the Botanical Research Institute of Texas 6: 9-15.

Jansen RK, Raubeson LA, Boore JL, Depamphilis CW, Chumley TW, Haberle RC, Wyman SK, Alverson AJ, Peery R, Herman SJ, Fourcade HM, Kuehl JV, McNeal JR, Leebens-Mack J, Cui L. 2005. Methods for obtaining and analyzing whole chloroplast genome sequences. Methods in Enzymology 395: 348-384 DOI 10.1016/S00766879(05)95020-9.

Jansen RK, Saski C, Lee SB, Hansen AK, Daniell H. 2011. Complete plastid genome sequences of three Rosids (Castanea, Prunus, Theobroma): evidence for at least two independent transfers of rpl22 to the nucleus. Molecular Biology \& Evolution 28: 835-847 DOI 10.1093/molbev/msq261.

Kamneva OK, Syring J, Liston A, Rosenberg NA. 2017. Evaluating allopolyploid origins in 
482

483

484

485

486

487

488

489

490

491

492

493

494

495

496

497

498

499

500

501

502

strawberries (Fragaria) using haplotypes generated from target capture sequencing. BMC Evolutionary Biology 17: 180 DOI 10.1186/s12862-017-1019-7.

Keeling PJ. 2004. Diversity and evolutionary history of plastids and their hosts. American Journal of Botany 91: 1481-1493 DOI 10.3732/ajb.91.10.1481.

Kong W Q, Yang J H. 2017. The complete chloroplast genome sequence of Morus cathayana and Morus multicaulis, and comparative analysis within genus Morus L. PeerJ 5: e3037 DOI 10.7717/peerj.3037.

Kuang DY, Wu H, Wang YL, Gao LM, Zhang SZ, Lu L. 2011. Complete chloroplast genome sequence of Magnolia kwangsiensis (Magnoliaceae): implication for DNA barcoding and population genetics. Genome 54: 663-673 DOI 10.1139/G11-026.

Kumar S, Nei M, Dudley J, Tamura K. 2008. MEGA: A biologist-centric software for evolutionary analysis of DNA and protein sequences. Briefings in Bioinformatics 9: 299306 DOI 10.1093/bib/bbn017.

Kurtz S, Choudhuri JV, Ohlebusch E, Schleiermacher C, Stoye J, Giegerich R. 2001. REPuter: the manifold applications of repeat analysis on a genomic scale. Nucleic Acids Research 29: 4633-4642 DOI 10.1093/nar/29.22.4633.

Laslett D, Canback B. 2004. ARAGORN, a program to detect tRNA genes and tmRNA genes in nucleotide sequences. Nucleic Acids Research 32: 11-16 DOI 10.1093/nar/gkh152.

Lei W, Ni D, Wang Y, Shao J, Wang X, Yang D, Wang J, Chen H, Liu C. 2016. Intraspecific and heteroplasmic variations, gene losses and inversions in the chloroplast genome of Astragalus membranaceus. Scientific Reports 6: 21669 DOI 10.1038/srep21669. 
503 Li R, Ma PF, Wen J, Yi TS. 2013. Complete sequencing of five araliaceae chloroplast genomes

504 and the phylogenetic implications. PLOS ONE 8: $\quad$ e78568 DOI

505

506

507

508

509

510

511

512

513

514

515

516

517

518

519

520

521

522

523

10.1371/journal.pone.0078568.

Librado P, Rozas J. 2009. DnaSP v5: a software for comprehensive analysis of DNA polymorphism data. Bioinformatics 25: 1451-1452 DOI 10.1093/bioinformatics/btp187.

Lin J, Davis TM. 2000. S1 analysis of long PCR heteroduplexes: detection of chloroplast indel polymorphisms in Fragaria. Theoretical \& Applied Genetics 101: 415-420 DOI $10.1007 / \mathrm{s} 001220051498$.

Lo EY, Donoghue MJ. 2012. Expanded phylogenetic and dating analyses of the apples and their relatives (Pyreae, Rosaceae). Molecular Phylogenetics \& Evolution 63: 230-243 DOI 10.1016/j.ympev.2011.10.005.

Lohse M, Drechsel O, Bock R. 2007. OrganellarGenomeDRAW (OGDRAW): a tool for the easy generation of high-quality custom graphical maps of plastid and mitochondrial genomes. Current Genetics 52: 267-274 DOI 10.1007/s00294-007-0161-y.

Luby JJ, Hancock JF, Dale A, Serçe S. 2008. Reconstructing Fragaria $\times$ ananassa utilizing wild $F$. virginiana and $F$. chiloensis: inheritance of winter injury, photoperiod sensitivity, fruit size, female fertility and disease resistance in hybrid progenies. Euphytica 163: 57-65 DOI 10.1007/s10681-007-9575-3.

Ma J, Yang B, Zhu W, Sun L, Tian J, Wang X. 2014. The complete chloroplast genome sequence of Mahonia bealei (Berberidaceae) reveals a significant expansion of the inverted repeat and phylogenetic relationship with other angiosperms". Gene 528: 120-131 DOI: 
10.1016/j.gene.2013.07.037.

525

526

527

528

529

530

531

532

533

534

535

536

537

538

539

540

541

542

543

544

Morton BR. 1998. Selection on the codon bias of chloroplast and cyanelle genes in different plant and algal lineages. Journal of Molecular Evolution 46: 449-459 DOI 10.1007/PL00006325.

Ni L, Zhao Z, Dorje G, Ma M. 2016. The complete chloroplast genome of Ye-Xing-Ba (Scrophularia dentata; Scrophulariaceae), an Alpine Tibetan Herb. PLOS ONE 11: e0158488 DOI 10.1371/journal.pone.0158488.

Njuguna W. 2010. Development and use of molecular tools in Fragaria. Ph.D Dissertation. Oregon State University, Corvallis, Oregon, USA.

Njuguna W, Liston A, Cronn R, Ashman TL, Bassil N. 2013. Insights into phylogeny, sex function and age of Fragaria based on whole chloroplast genome sequencing. Molecular Phylogenetics \& Evolution 66: 17-29 DOI 10.1016/j.ympev.2012.08.026.

Noguchi Y. 2011. 'Tokun': A new decaploid interspecific hybrid strawberry having the aroma of the wild strawberry. Journal of Japan Association on Odor Environment 42: 122-128.

Palmer JD. 1985. Comparative organization of chloroplast genomes. Annual Review of Genetics 19: 325 DOI 10.1146/annurev.ge.19.120185.001545.

Palmer JD. 1991. Plastid chromosomes: structure and evolution. The Molecular Biology of Plastids 7: 5-53.

Palmer JD. 1986. Chloroplast DNA and phylogenetic relationships. In S. K. Dutta [ed.], DNA systematics, Vol. II, Plants. CRC Press, Boca Raton, Florida, USA.

Potter D, Eriksson T, Evans RC, Oh S, Smedmark JEE, Morgan DR, Kerr M, Robertson 
KR, Arsenault M, Dickinson TA, Campbell CS. 2007. Phylogeny and classification of

Rosaceae. Plant Systematics and Evolution 266: 5-43 DOI 10.1007/s00606-007-0539-9.

547

548

549

550

551

552

553

554

555

556

557

558

559

560

561

562

563

564

565

Potter D, Luby JJ, Harrison RE. 2000. Phylogenetic relationships among species of Fragaria (Rosaceae) inferred from non-coding nuclear and chloroplast DNA sequences. Systematic Botany 25: 337-348 DOI 10.2307/2666646.

Powell W, Morgante M, McDevitt R, Vendramin GG, Rafalski JA. 1995. Polymorphic simple sequence repeat regions in chloroplast genomes: applications to the population genetics of pines. Proceedings of the National Academy of Sciences USA 92: 7759-7763.

Rousseau-Gueutin M, Gaston A, Aïnouche A, Aïnouche ML, Olbricht K, Staudt G, Richard L, Denoyesrothan B. 2009. Tracking the evolutionary history of polyploidy in Fragaria L. (strawberry): new insights from phylogenetic analyses of low-copy nuclear genes. Molecular Phylogenetics \& Evolution 51: 515-530 DOI 10.1016/j.ympev.2008.12.024.

Salamone I, Govindarajulu R, Falk S, Parks M, Liston A, Ashman TL. 2013. Bioclimatic, ecological, and phenotypic intermediacy and high genetic admixture in a natural hybrid of octoploid strawberries. American Journal of Botany 100: 939-950 DOI 10.3732/ajb.1200624.

Sargent DJ. 2005. A genetic investigation of diploid Fragaria. Ph.D. Thesis. The University of Reading, Reading, UK.

Schattner P, Brooks AN, Lowe TM. 2005. The tRNAscan-SE, snoscan and snoGPS web servers for the detection of tRNAs and snoRNAs. Nucleic Acids Research 33: W686-W689 
DOI 10.1093/nar/gki366.

567

Schumann CM, Hancock JF. 1989. Paternal inheritance of plastids in Medicago sativa. Tagtheoretical \& Applied Geneticstheoretische Und Angewandte Genetik 78: 863-866.

Shaw J, Lickey EB, Schilling EE, Small RL. 2007. Comparison of whole chloroplast genome sequences to choose noncoding regions for phylogenetic studies in angiosperms: The Tortoise and the Hare III. American Journal of Botany 94: 275-288 DOI 10.3732/ajb.94.3.275.

Shen L, Guan Q, Amin A, Wei Z, Li M, Li X, Lin Z, Tian J. 2016. Complete plastid genome of Eriobotrya japonica (Thunb.) Lindl and comparative analysis in Rosaceae. Springerplus 5: 2036 DOI 10.1186/s40064-016-3702-3.

Shulaev V, Sargent DJ, Crowhurst RN, Mockler TC, Folkerts O, Delcher AL, Jaiswal P, Mockaitis K, Liston A, Mane SP, Burns P, Davis TM, Slovin JP, Bassil N, Hellens RP, Evans C, Harkins T, Kodira C, Desany B, Crasta OR, Jensen RV, Allan AC, Michael TP, Setubal JC, Celton JM, Rees DJ, Williams KP, Holt SH, Ruiz Rojas JJ, Chatterjee M, Liu B, Silva H, Meisel L, Adato A, Filichkin SA, Troggio M, Viola R, Ashman TL, Wang H, Dharmawardhana P, Elser J, Raja R, Priest HD, Bryant DW Jr, Fox SE, Givan SA, Wilhelm LJ, Naithani S, Christoffels A, Salama DY, Carter J, Lopez Girona E, Zdepski A, Wang W, Kerstetter RA, Schwab W, Korban SS, Davik J, Monfort A, Denoyes-Rothan B, Arus P, Mittler R, Flinn B, Aharoni A, Bennetzen JL, Salzberg SL, Dickerman AW, Velasco R, Borodovsky M, Veilleux RE, Folta KM. 2011. The genome of woodland strawberry (Fragaria vesca). Nature Genetics 43: 109-116 DOI 
Small RL, Ryburn JA, Cronn RC, Seelanan T, Wendel JF. 1998. The tortoise and the hare:

Smith SE, Bingham ET, Fulton RW. 1986. Transmission of chlorophyll deficiencies in Medicago sativa Evidence for biparental inheritance of plastids. Heredity 77: 35-38.

Staudt G. 2009. Strawberry biogeography, genetics and systematics. Acta Horticulturae 842: 71-84 DOI 10.17660/ActaHortic.2009.842.1.

Taberlet P, Gielly L, Pautou G, Bouvet J. 1991. Universal primers for amplification of three non-coding regions of chloroplast DNA. Plant Molecular Biology 17: 1105-1109.

Takeuchi T, Fujinami H, Kawata T, Matsumura M. 1999. Pedigree and characteristics of a new strawberry cultivar 'Beni hoppe'. Bulletin of the Shizuoka Agricultural Experiment Station 44: 13-24.

\section{Terakami S, Matsumura Y, Kurita K, Kanamori H, Katayose Y, Yamamoto T, Katayama} H. 2012. Complete sequence of the chloroplast genome from pear (Pyrus pyrifolia): genome structure and comparative analysis. Tree Genetics \& Genomes 8: 841-854 DOI 10.1007/s11295-012-0469-8.

Tennessen JA, Govindarajulu R, Liston A, Ashman TL. 2013. Targeted sequence capture provides insight into genome structure and genetics of male sterility in a gynodioecious diploid strawberry, Fragaria vesca ssp. bracteata (Rosaceae). G3: Genes, Genomes, 
Genetics 3: 1341-1351 DOI 10.1534/g3.113.006288.

609 Testolin R, Cipriani G. 1997. Paternal inheritance of chloroplast DNA and maternal inheritance DOI $10.1007 / \mathrm{s} 001220050493$.

Thiel T, Michalek W, Varshney R, Graner A. 2003. Exploiting EST databases for the development and characterization of gene-derived SSR-markers in barley ( Hordeum vulgare L.). Theoretical \& Applied Genetics 106: 411-422 DOI 10.1007/s00122-002-10310 .

Thompson JD, Gibson TJ, Plewniak F, Jeanmougin F, Higgins DG. 1997. The CLUSTAL_X windows interface: flexible strategies for multiple sequence alignment aided by quality analysis tools. Nucleic Acids Research 25: 4876-4882 DOI 10.1093/nar/25.24.4876.

VanBuren R, Bryant D, Bushakra JM, Vining KJ, Edger PP, Rowley ER, Priest HD, Michael TP, Lyons E, Filichkin SA, Dossett M, Finn CE, Bassil NV, Mockler TC. 2016. 10.1111/tpj.13215.

Velasco R, Zharkikh A, Affourtit J, Dhingra A, Cestaro A, Kalyanaraman A, Fontana P, Bhatnagar SK, Troggio M, Pruss D, Salvi S, Pindo M, Baldi P, Castelletti S, Cavaiuolo The genome of black raspberry (Rubus occidentalis). the Plant Journal 87: 535-547 DOI M, Coppola G, Costa F, Cova V, Dal Ri A, Goremykin V, Komjanc M, Longhi S, Magnago P, Malacarne G, Malnoy M, Micheletti D, Moretto M, Perazzolli M, SiAmmour A, Vezzulli S, Zini E, Eldredge G, Fitzgerald LM, Gutin N, Lanchbury J, Macalma T, Mitchell JT, Reid J, Wardell B, Kodira C, Chen Z, Desany B, Niazi F, 
Palmer M, Koepke T, Jiwan D, Schaeffer S, Krishnan V, Wu C, Chu VT, King ST,

A, Kater MM, Masiero S, Lasserre P, Lespinasse Y, Allan AC, Bus V, Chagné D,

Crowhurst RN, Gleave AP, Lavezzo E, Fawcett JA, Proost S, Rouzé P, Sterck L,

Toppo S, Lazzari B, Hellens RP, Durel CE, Gutin A, Bumgarner RE, Gardiner SE,

Skolnick M, Egholm M, Van de Peer Y, Salamini F, Viola R. 2010. The genome of the domesticated apple (Malus × domestica Borkh.). Nature Genetics 42: 833-839 DOI $10.1038 /$ ng. 654 .

Verde I, Abbott AG, Scalabrin S, Jung S, Shu S, Marroni F, Zhebentyayeva T, Dettori MT, Grimwood J, Cattonaro F, Zuccolo A, Rossini L, Jenkins J, Vendramin E, Meisel LA, Decroocq V, Sosinski B, Prochnik S, Mitros T, Policriti A, Cipriani G, Dondini L,

Ficklin S, Goodstein DM, Xuan P, Del Fabbro C, Aramini V, Copetti D, Gonzalez S, Horner DS, Falchi R, Lucas S, Mica E, Maldonado J, Lazzari B, Bielenberg D, Pirona R, Miculan M, Barakat A, Testolin R, Stella A, Tartarini S, Tonutti P, Arús P, M, Rokhsar DS. 2013. The high-quality draft genome of peach (Prunus persica) identifies unique patterns of genetic diversity, domestication and genome evolution. Nature Genetics

Vieira LDN, Faoro H, Fraga HPDF, Rogalski M, Souza EMD, Pedrosa FDO, Nodari RO, 
650

651

652

653

654

655

656

657

658

659

660

661

662

663

664

665

666

667

668

669

670

Vining KJ, Salina N, Tennessen JA, Zurn JD, Sargent DJ, Hancock J, Bassil NV. 2017. Genotyping-by-sequencing enables linkage mapping in three octoploid cultivated strawberry families. PeerJ 5: e3731 DOI 10.7717/peerj.3731.

Wang F, Gao ZH, Qiao YS, Mi L, Li JF, Zhang Z, Wang M, Lin ZL, Gu XB. 2014. RdreB1BI gene expression driven by the stress-induced promoter rd29A enhances resistance to cold stress in Benihope strawberry. Acta Horticulturae 1049: 975-988 DOI 10.17660/ActaHortic.2014.1049.159.

Wang RJ, Cheng CL, Chang CC, Wu CL, Su TM, Chaw SM. 2008. Dynamics and evolution of the inverted repeat-large single copy junctions in the chloroplast genomes of monocots. BMC Evolutionary Biology 8: 36 DOI 10.1186/1471-2148-8-36.

Wang S, Shi C, Gao LZ. 2013. Plastid genome sequence of a wild woody oil species, Prinsepia utilis, provides insights into evolutionary and mutational patterns of Rosaceae chloroplast genomes. PLOS ONE 8: e73946 DOI 10.1371/journal.pone.0073946.

Wei W, Youliang Z, Li C, Yuming W, Zehong Y, Ruiwu Y. 2005. PCR-RFLP analysis of cpDNA and mtDNA in the genus Houttuynia in some areas of China. Hereditas 142: 24-32 DOI 10.1111/j.1601-5223.2005.01704.x.

Wu J, Wang Z, Shi Z, Zhang S, Ming R, Zhu S, Khan MA, Tao S, Korban SS, Wang H, Chen NJ, Nishio T, Xu X, Cong L, Qi K, Huang X, Wang Y, Zhao X, Wu J, Deng C,Gou C, Zhou W, Yin H, Qin G, Sha Y, Tao Y, Chen H, Yang Y, Song Y, Zhan D, Wang J, Li L, Dai M, Gu C, Wang Y, Shi D, Wang X, Zhang H, Zeng L, Zheng D, Wang C,Chen M, Wang G, Xie L, Sovero V, Sha S, Huang W, Zhang S, Zhang M, Sun 
671

672

673

674

675

676

677

678

679

680

681

682

683

684

685

686

687

688

689

690

691

J, Xu L, Li Y, Liu X, Li Q, Shen J, Wang J, Paull RE, Bennetzen JL, Wang J, Zhang S. 2013. The genome of pear (Pyrus bretschneideri Rehd.). Genome Research 23: 396-408 DOI 10.1101/gr.144311.112.

Wyman SK, Jansen RK, Boore JL. 2004. Automatic annotation of organellar genomes with DOGMA. Bioinformatics 20: 3252-3255 DOI 10.1093/bioinformatics/bth352.

Xiang Y, Huang CH, Hu Y, Wen J, Li S, Yi T, Chen H, Xiang J, Ma H. 2017. Evolution of Rosaceae fruit types based on nuclear phylogeny in the context of geological times and genome duplication. Molecular Biolology Evolution 34: 262-281 DOI $10.1093 / \mathrm{molbev} / \mathrm{msw} 242$.

Xue J, Wang S, Zhou SL. 2012. Polymorphic chloroplast microsatellite loci in Nelumbo (Nelumbonaceae). American Journal of Botany 99: 240-244 DOI 10.3732/ajb.1100547.

Yao X, Tang P, Li Z, Li D, Liu Y, Huang H. 2015. The first complete chloroplast genome sequences in Actinidiaceae: genome structure and comparative analysis. PLOS ONE 10: e0129347 DOI 10.1371/journal.pone.0129347.

Zhang Q, Chen W, Sun L, Zhao F, Huang B, Yang W, Tao Y, Wang J, Yuan Z, Fan G. Xing Z, Han C, Pan H, Zhong X, Shi W, Liang X, Du D, Sun F, Xu Z, Hao R, Lv T, Lv Y, Zheng Z, Sun M, Luo L, Cai M, Gao Y, Wang J, Yin Y, Xu X, Cheng T, Wang J. 2012. The genome of Prunus mume. Nature Communications 3: 1318 DOI 10.1038/ncomms2290.

Zhang SD, Jin JJ, Chen SY, Chase MW, Soltis DE, Li HT, Yang JB, Li DZ, Yi TS. 2017. Diversification of Rosaceae since the Late Cretaceous based on plastid phylogenomics. New 
Phytologist 214: 1355-1367 DOI 10.1111/nph.14461.

693

694

695

696

Zhang Y, Ma J, Yang B, Li R, Zhu W, Sun L, Tian J, Zhang L. 2014. The complete chloroplast genome sequence of Taxus chinensis var. mairei (Taxaceae): loss of an inverted repeat region and comparative analysis with related species. Gene 540: 201-209 DOI 10.1016/j.gene.2014.02.037. 


\section{Figure 1}

Gene map of the $F . \times$ ananassa 'Benihoppe' chloroplast genome.

Genes inside the circle are transcribed in the clockwise direction, and those outside are transcribed in the counter-clockwise direction. Color coding indicates genes of different functional groups. The dark-gray inner circle denotes the GC content, and the lighter-gray circle denotes the AT content. 
$\square$ photosystem I photosystem II

cytochrome b/f complex ATP synthase

NADH dehydrogenase

RubisCO large subunit

RNA polymerase

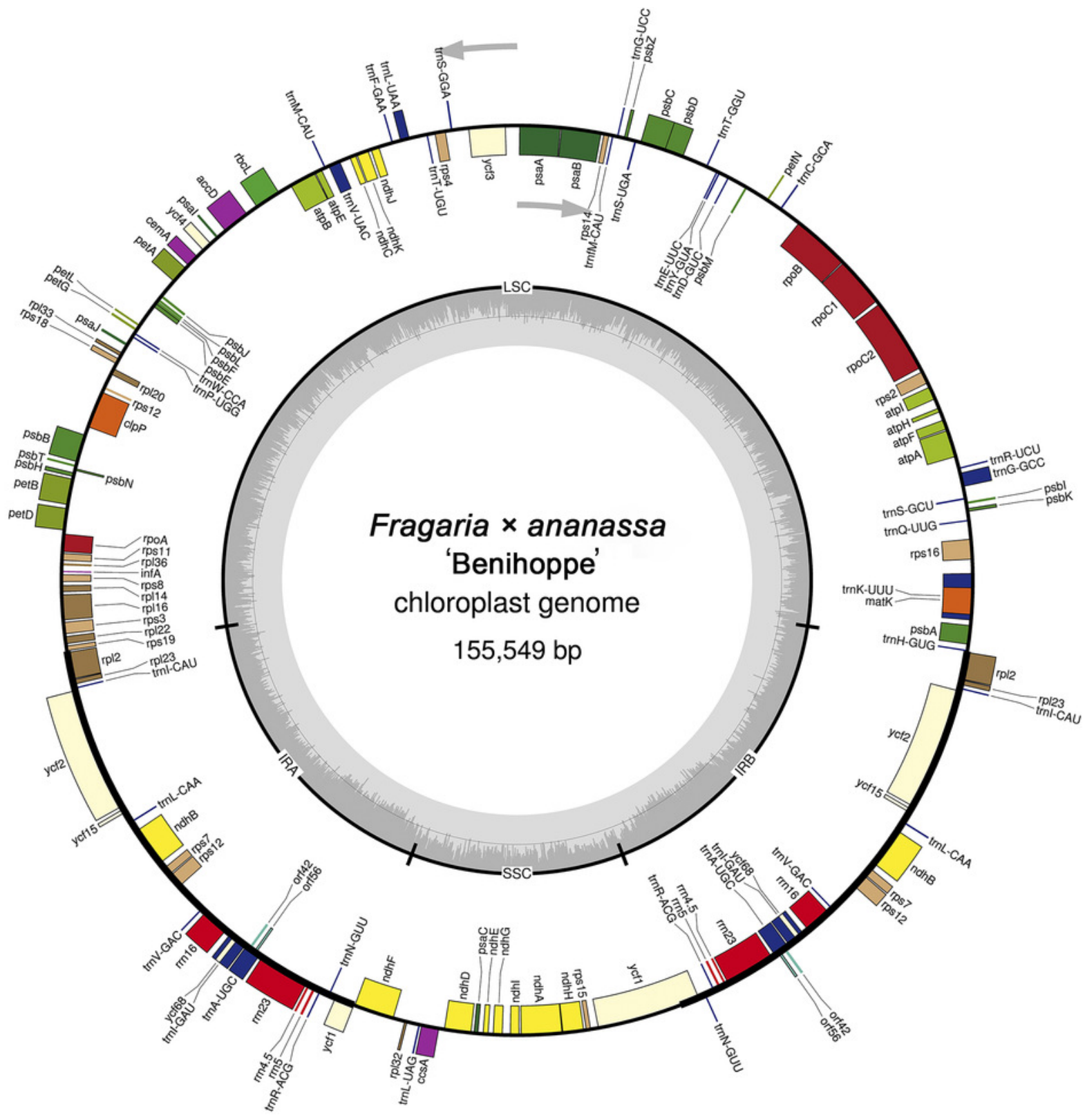

(

ribosomal proteins (LSU)

clpP, matK

hypothetical chloroplast reading frames (ycf)

ORFs

transfer RNAs

ribosomal RNAs 


\section{Figure 2}

Whole-chloroplast-genome alignments for nine Rosaceae species obtained using the mVISTA program, with the $F . \times$ ananassa 'Benihoppe' chloroplast genome as the reference.

The Y-scale indicates identity from 50\% to 100\%. Gray arrows indicate the position and direction of each gene. Red indicates non-coding sequences (CNS); blue indicates the exons of protein-coding genes (exon); and lime green indicates the introns of protein-coding genes (intron).
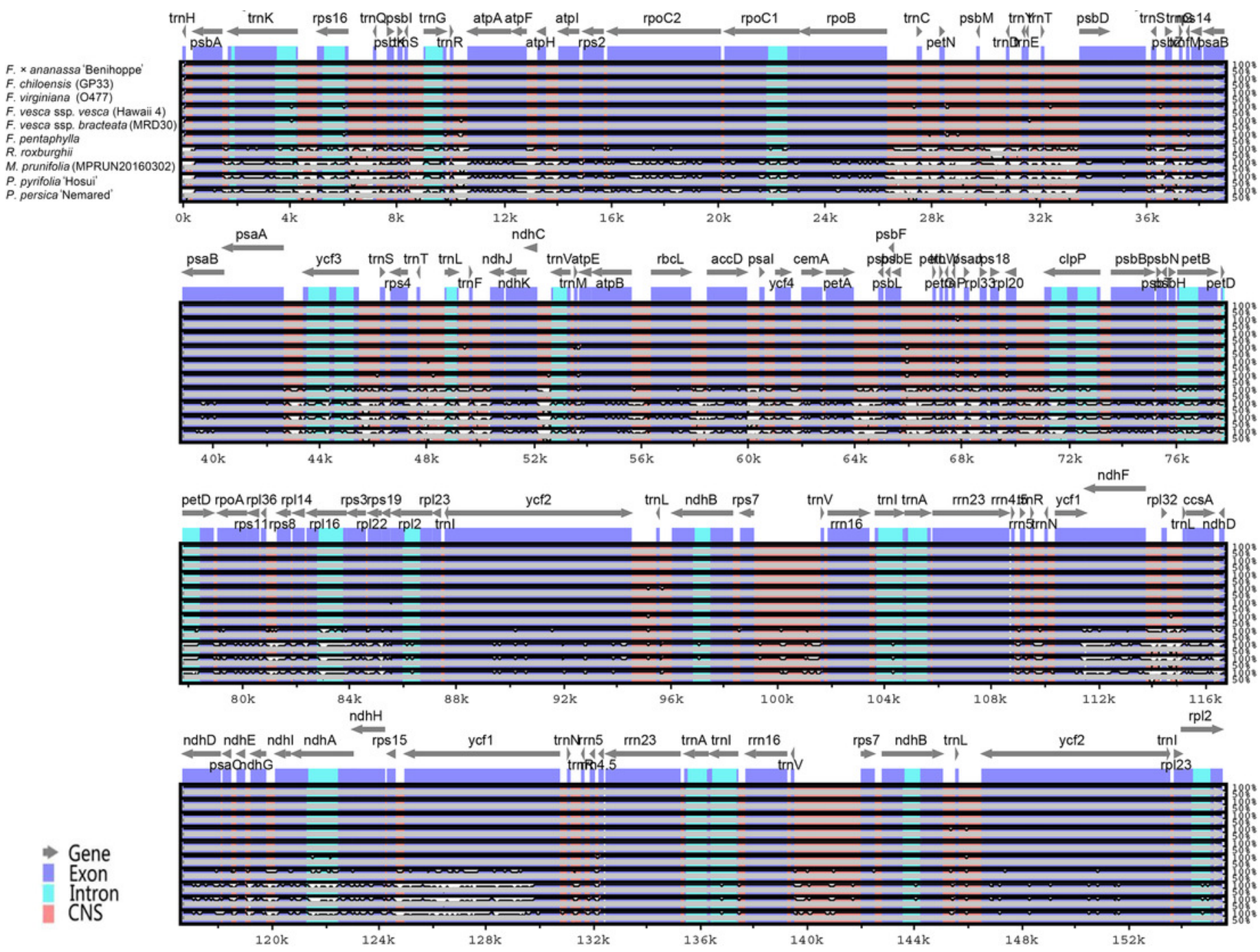
Figure 3

Comparison of the borders of LSC, SSC and IR regions in nine Rosaceae chloroplast genomes. 
F. × ananassa

'Benihoppe'

F. chiloensis

(GP33)

F. virginiana
(O477)

F. virginian
(0477)

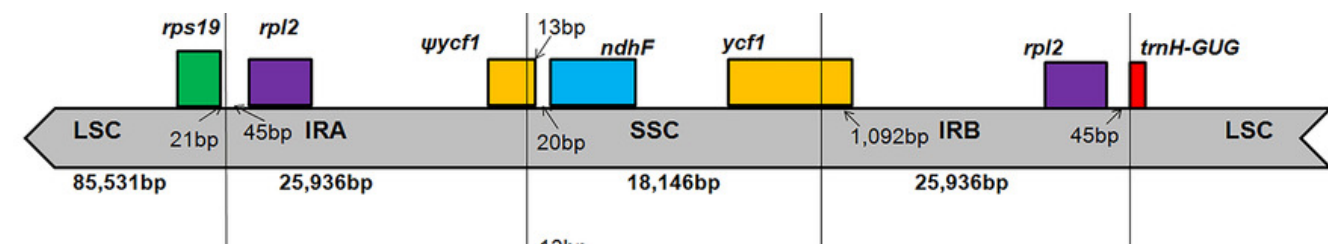
(Hawaii 4)

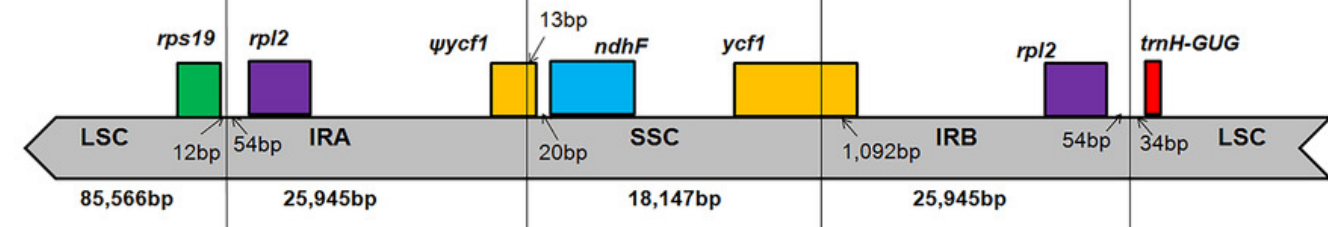

vesca ssp. bracteata (MRD30)

F. pentaphylla

R. roxburghii
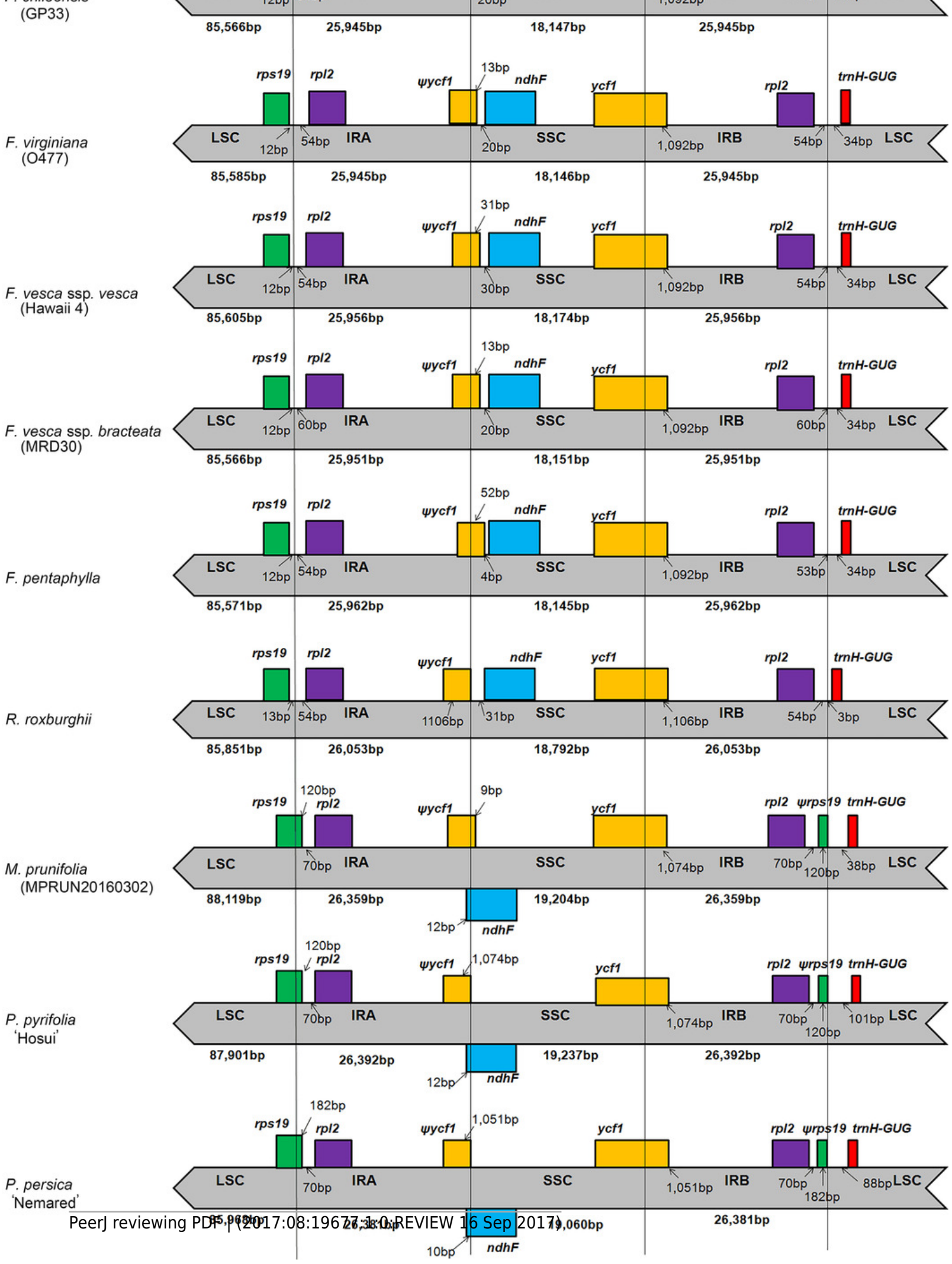


\section{Figure 4}

Ka/Ks ratios of 78 protein-coding genes in Fragaria, Rosa, Malus, Pyrus and Prunus.

Blue boxes indicate the Ka/Ks ratio for Fragaria vs. Rosa; red, Fragaria vs. Malus; green, Fragaria vs. Pyrus; and purple, Fragaria vs. Prunus. 
uFragaria vs Rasa a Fragaria vs Malus u Fragania vs Pyrus a Fragaria vs Prunus
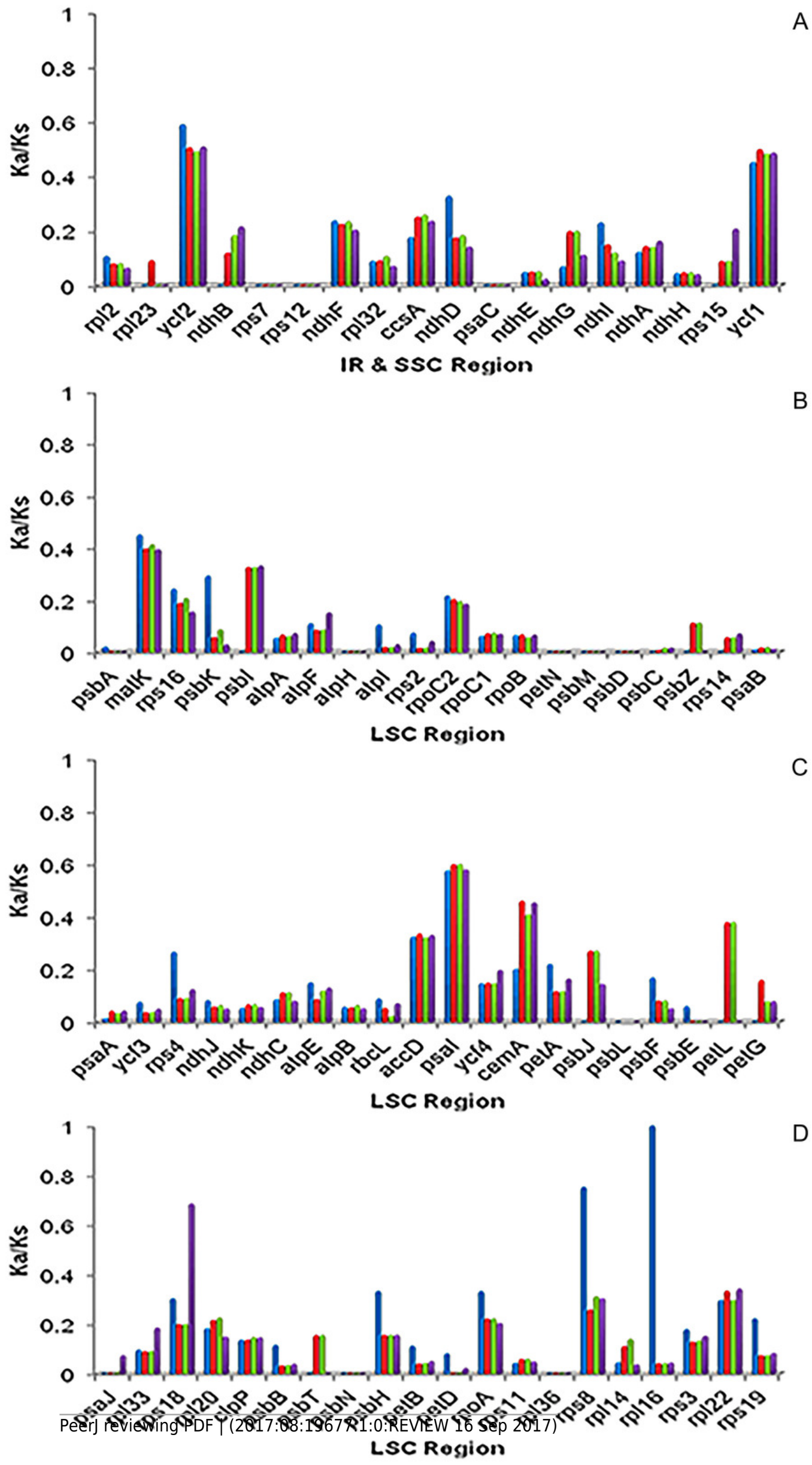
Figure 5

Percentage of variable sites and number of parsimony-informative sites in non-coding regions across the ten Fragaria chloroplast genomes.

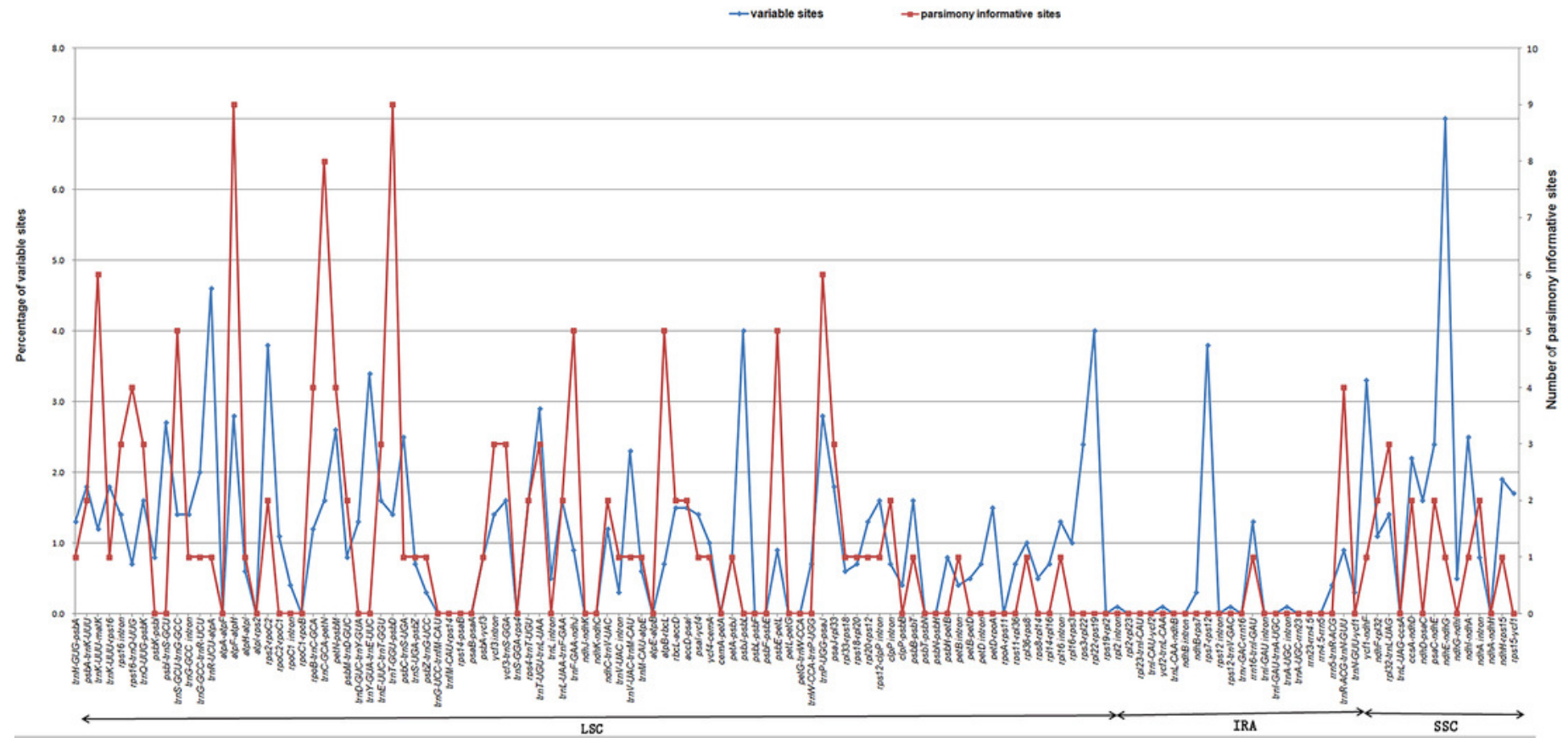




\section{Table $\mathbf{1}$ (on next page)}

Summary of the complete chloroplast genome characteristics of ten species in Rosaceae. 


\begin{tabular}{|c|c|c|c|c|c|c|c|c|c|c|c|c|}
\hline Species & $\begin{array}{l}\text { Genome } \\
\text { size (bp) }\end{array}$ & $\begin{array}{l}\text { LSC size } \\
\text { (bp) }\end{array}$ & $\begin{array}{l}\text { SSC size } \\
\text { (bp) }\end{array}$ & $\begin{array}{l}\text { IR size } \\
\text { (bp) }\end{array}$ & $\begin{array}{l}\text { Number } \\
\text { of genes }\end{array}$ & $\begin{array}{l}\text { Protein } \\
\text {-coding } \\
\text { genes }\end{array}$ & $\begin{array}{l}\text { tRNA } \\
\text { genes }\end{array}$ & $\begin{array}{l}\text { rRNA } \\
\text { genes }\end{array}$ & $\begin{array}{l}\text { Number } \\
\text { of genes } \\
\text { duplicated } \\
\text { in IR }\end{array}$ & $\begin{array}{l}\text { GC } \\
\text { content } \\
(\%)\end{array}$ & $\begin{array}{l}\text { GenBank } \\
\text { no. }\end{array}$ & Reference \\
\hline $\begin{array}{l}F . \times \text { ananassa } \\
\text { 'Benihoppe' }\end{array}$ & 155,549 & 85,531 & 18,146 & 25,936 & 112 & $78(7)$ & $30(7)$ & $4(4)$ & 18 & $37.23 \%$ & KY358226 & This article \\
\hline F. chiloensis (GP33) & 155,603 & 85,566 & 18,147 & 25,945 & 112 & $78(7)$ & $30(7)$ & $4(4)$ & 18 & $37.22 \%$ & JN884816 & Salamone et al., 2013 \\
\hline F. virginiana $(\mathrm{O} 477)$ & 155,621 & 85,585 & 18,146 & 25,945 & 112 & $78(7)$ & $30(7)$ & $4(4)$ & 18 & $37.23 \%$ & JN884817 & Salamone et al., 2013 \\
\hline $\begin{array}{l}\text { F. vesca ssp. vesca } \\
\text { (Hawaii 4) }\end{array}$ & 155,691 & 85,605 & 18,174 & 25,956 & 112 & $78(7)$ & $30(7)$ & $4(4)$ & 18 & $37.21 \%$ & JF345175 & Shulaev et al., 2011 \\
\hline $\begin{array}{l}\text { F. vesca } \mathrm{ssp} . \\
\text { bracteata (MRD30) }\end{array}$ & 155,619 & 85,566 & 18,151 & 25,951 & 112 & $78(7)$ & $30(7)$ & $4(4)$ & 18 & $37.23 \%$ & KC507755 & Unpublished \\
\hline F. pentaphylla & 155,640 & 85,571 & 18,145 & 25,962 & 112 & $78(7)$ & $30(7)$ & $4(4)$ & 18 & $37.25 \%$ & KY434061 & Bai et al., 2017 \\
\hline R. roxburghii & 156,749 & 85,851 & 18,792 & 26,053 & 114 & $79(7)$ & $31(7)$ & $4(4)$ & 18 & $37.23 \%$ & KX768420 & Unpublished \\
\hline $\begin{array}{l}\text { M. prunifolia } \\
\text { (MPRUN20160302) }\end{array}$ & 160,041 & 88,119 & 19,204 & 26,359 & 111 & $77(7)$ & $30(7)$ & $4(4)$ & 18 & $36.56 \%$ & KU851961 & Bao et al., 2016 \\
\hline P. pyrifolia 'Hosui' & 159,922 & 87,901 & 19,237 & 26,392 & 111 & $77(6)$ & $30(7)$ & $4(4)$ & 17 & $36.58 \%$ & AP012207 & Terakami et al., 2012 \\
\hline P. persica 'Nemared' & 157,790 & 85,968 & 19,060 & 26,381 & 112 & $78(5)$ & $30(7)$ & $4(4)$ & 16 & $36.76 \%$ & HQ336405 & Jansen et al., 2011 \\
\hline
\end{tabular}

1 Notes.

2 LSC, large single copy; SSC, small single copy; IR, inverted repeat (A/B); bp, base pairs.

3 Figures in brackets denote the number of genes duplicated in IR. 
Table 2 (on next page)

List of annotated genes in the $F . \times$ ananassa 'Benihoppe' chloroplast genome. 


\begin{tabular}{|c|c|c|c|c|c|c|}
\hline Category & Gene group & Gene name & & & & \\
\hline \multirow[t]{12}{*}{ Photosynthesis } & Subunits of photosystem I & $p s a A$ & $p s a B$ & $p s a C$ & psaI & $p s a J$ \\
\hline & Subunits of photosystem II & $p s b A$ & $p s b B$ & $p s b C$ & $p s b D$ & $p s b E$ \\
\hline & & $p s b F$ & $p s b H$ & $p s b I$ & $p s b J$ & $p s b K$ \\
\hline & & $p s b L$ & $p s b M$ & $p s b N$ & $p s b T$ & $p s b Z$ \\
\hline & Subunits of NADH dehydrogenase & $n d h A^{\mathrm{b}}$ & $n d h B^{\mathrm{b}, \mathrm{c}}$ & $n d h C$ & $n d h D$ & $n d h E$ \\
\hline & & $n d h F$ & $n d h G$ & $n d h H$ & $n d h I$ & $n d h J$ \\
\hline & & $n d h K$ & & & & \\
\hline & Subunits of cytochrome b/f complex & petA & $\operatorname{pet} B^{\mathrm{b}}$ & $\operatorname{pet} D^{\mathrm{b}}$ & $\operatorname{pet} G$ & pet $L$ \\
\hline & & $\operatorname{petN}$ & & & & \\
\hline & Subunits of ATP synthase & $\operatorname{atp} A$ & $\operatorname{atp} B$ & $\operatorname{atp} E$ & $a t p F$ & $\operatorname{atpH}$ \\
\hline & & atpI & & & & \\
\hline & Large subunit of rubisco & $r b c L$ & & & & \\
\hline \multirow[t]{8}{*}{ Self-replication } & Proteins of large ribosomal subunit & $r p l 2^{\mathrm{b}, \mathrm{c}}$ & rpl14 & $\operatorname{rpl16^{\mathrm {b}}}$ & rpl20 & $r p l 23^{\mathrm{c}}$ \\
\hline & & rpl32 & rpl33 & rpl36 & & \\
\hline & Proteins of small ribosomal subunit & $r p s 2$ & rps3 & rps4 & $\operatorname{rps} 7^{\mathrm{c}}$ & rps8 \\
\hline & & rps11 & $\operatorname{rps} 12^{\mathrm{b}, \mathrm{c}}$ & $\operatorname{rps} 14$ & $\operatorname{rps} 15$ & $\operatorname{rps} 16^{\mathrm{b}}$ \\
\hline & & $\operatorname{rps} 18$ & $\operatorname{rps} 19$ & & & \\
\hline & Subunits of RNA polymerase & rроA & rров & $r p o C 1^{\text {b }}$ & rpoC2 & \\
\hline & Ribosomal RNAs & $\operatorname{rrn} 16^{\mathrm{c}}$ & $r r n 23^{\mathrm{c}}$ & $\operatorname{rrn} 4.5^{\mathrm{c}}$ & $r r n 5^{c}$ & \\
\hline & Transfer RNAs & $\operatorname{trn} A-U G C^{\mathrm{b}, \mathrm{c}}$ & $\operatorname{trn} C-G C A$ & $\operatorname{trn} D-G U C$ & $\operatorname{trnE-UUC}$ & $\operatorname{trnF-GAA}$ \\
\hline
\end{tabular}




\begin{tabular}{|c|c|c|c|c|c|c|}
\hline & & $\operatorname{trn} G-G C C^{\mathrm{b}}$ & $\operatorname{trn} G-U C C$ & $\operatorname{trn} H-G U G$ & $\operatorname{trnI}-C A U^{c}$ & $\operatorname{trnI}-G A U^{\mathrm{b}, \mathrm{c}}$ \\
\hline & & $\operatorname{trnK}-U U U^{\mathrm{b}}$ & $\operatorname{trn} L-C A A^{\mathrm{c}}$ & $\operatorname{trn} L-U A A^{\mathrm{b}}$ & $\operatorname{trn} L-U A G$ & $\operatorname{trnfM}-C A U$ \\
\hline & & $\operatorname{trnM}-C A U$ & $\operatorname{trnN}-G U U^{c}$ & $\operatorname{trn} P-U G G$ & $\operatorname{trn} Q-U U G$ & $\operatorname{trn} R-A C G^{c}$ \\
\hline & & $\operatorname{trnR}-U C U$ & $\operatorname{trn} S-G C U$ & $\operatorname{trn} S-G G A$ & $\operatorname{trn} S-U G A$ & $\operatorname{trn} T-G G U$ \\
\hline & & $\operatorname{trnT} T-U G U$ & $\operatorname{trn} V-G A C^{c}$ & $\operatorname{trn} V-U A C^{b}$ & $\operatorname{trn} W-C C A$ & $\operatorname{trn} Y-G U A$ \\
\hline \multirow[t]{6}{*}{ Other genes } & Maturase & matK & & & & \\
\hline & Protease & $\operatorname{clp} P^{\mathrm{a}}$ & & & & \\
\hline & Envelope membrane protein & сетA & & & & \\
\hline & Acetyl-CoA carboxylase & $a c c D$ & & & & \\
\hline & c-type cytochrome synthesis gene & $\operatorname{ccs} A$ & & & & \\
\hline & Translation initiation factor & $\inf A^{\mathrm{d}}$ & & & & \\
\hline \multirow[t]{2}{*}{ Genes of unknown function } & Conserved hypothetical chloroplast ORF & $y c f 1^{\mathrm{c}}$ & $y c f 2^{\mathrm{c}}$ & $y c f 3^{\mathrm{a}}$ & $y c f 4$ & $y c f 15^{\mathrm{c}, \mathrm{d}}$ \\
\hline & & $y c f 68^{\mathrm{c}, \mathrm{d}}$ & $\operatorname{orf} 42^{\mathrm{c}}$ & $\operatorname{orf} 56^{\mathrm{c}}$ & & \\
\hline
\end{tabular}

\section{Notes.}

2 a Gene with two introns.

$3 \quad{ }^{b}$ Gene with one intron.

$4 \quad{ }^{\mathrm{c}}$ Genes located in the inverted repeats.

5 d Pseudogene. 


\section{Table 3 (on next page)}

Distribution of simple sequence repeat (SSR) loci in the $F . \times$ ananassa 'Benihoppe' chloroplast genome. 


\begin{tabular}{|c|c|c|c|}
\hline $\begin{array}{l}\text { Repeat } \\
\text { motif }\end{array}$ & $\begin{array}{l}\text { Length } \\
\text { (bp) }\end{array}$ & $\begin{array}{l}\text { Number of } \\
\text { SSRs }\end{array}$ & Start position ${ }^{a, b}$ \\
\hline \multirow[t]{6}{*}{ A } & 10 & 11 & $\begin{array}{l}3744^{*} ; 7019 ; 7609 ; 8256 ; 26933 ; 47455 ; 60427 ; 65327 \\
(p s b F) ; 66476 ; 69482 ; 109237 ;\end{array}$ \\
\hline & 11 & 2 & $15732 ; 139818$ \\
\hline & 12 & 2 & $7853 ; 136910^{*}$ \\
\hline & 15 & 1 & 8608 \\
\hline & 16 & 1 & 36532 \\
\hline & 17 & 1 & 7969 \\
\hline \multirow[t]{6}{*}{$\mathrm{T}$} & 10 & 8 & $\begin{array}{l}\text { 15712; } 25631(\text { rpoB); } 46143 ; 55594(\text { atpB }) ; 61734 ; \\
121755^{*} ; 128786(y c f 1) ; 131836\end{array}$ \\
\hline & 11 & 6 & 12219; 17914 (гроС2 ); 45448; 60613; 101254; 119816 \\
\hline & 12 & 2 & $27869 ; 104161^{*}$ \\
\hline & 14 & 1 & 70953 \\
\hline & 15 & 1 & 71654 \\
\hline & 16 & 1 & 64340 \\
\hline G & 12 & 1 & 64213 \\
\hline AT & 10 & 5 & $7065 ; 29392 ; 37199 ; 60337 ; 120666$ \\
\hline \multirow[t]{2}{*}{ TA } & 10 & 5 & 4891; 6971; 19292 (rрос2 ); 52497; 121687* \\
\hline & 12 & 5 & $1663 ; 6993 ; 7053 ; 36475 ; 60325$ \\
\hline $\mathrm{TC}$ & 10 & 1 & $62100($ cemA $)$ \\
\hline AAT & 12 & 1 & $127596(y c f 1)$ \\
\hline ATA & 12 & 1 & $154754 *$ \\
\hline TAT & 12 & 1 & $86317^{*}$ \\
\hline AAAT & 12 & 1 & 55693 \\
\hline AATA & 12 & 1 & 6423 \\
\hline ATGT & 12 & 1 & $79222($ rроA) \\
\hline TATT & 12 & 1 & $72668^{*}$ \\
\hline
\end{tabular}

1 Notes.

$2 \quad{ }^{a}$ The SSR-containing coding regions are indicated in parentheses.

$3 \quad{ }^{b}$ Asterisk denote the SSR-containing introns. 


\section{Table 4 (on next page)}

$\mathrm{Ka} / \mathrm{Ks}$ ratio of protein-coding genes from three Rosaceae species for comparsion with Fragaria. 


\begin{tabular}{lcccc}
\hline Region & $\begin{array}{c}\text { Fragaria } \\
\text { vs }\end{array}$ & $\begin{array}{c}\text { Fragaria } \\
\text { vs } \\
\text { Rosa }\end{array}$ & $\begin{array}{c}\text { Fragaria } \\
\text { valus }\end{array}$ & $\begin{array}{c}\text { Fragaria } \\
\text { vs }\end{array}$ \\
& 0.14101 & 0.11975 & 0.11924 & Prunus \\
\hline LSC & 0.11607 & 0.11744 & 0.12212 & 0.11595 \\
IR & 0.14942 & 0.15972 & 0.15895 & 0.13104 \\
SSC & & & & 0.14729 \\
\hline
\end{tabular}

1 


\section{Table 5 (on next page)}

SNPs and InDels among the $F . \times$ ananassa 'Benihoppe', $F$. chiloensis (GP33) and $F$. virginiana (0477) chloroplast genomes. 


\begin{tabular}{|c|c|c|c|c|c|c|c|}
\hline Number & Type & Position & Location & Nucleotide position $^{b}$ & F. $\times$ ananassa 'Benihoppe' & F. chiloensis (GP33) & F. virginiana (O477) \\
\hline 1 & SNP & $\mathrm{LSC} /$ trnK-rps 16 & $\mathrm{CNS}^{\mathrm{a}}$ & 4274 & $\mathrm{C}$ & $\mathrm{A}$ & $\mathrm{C}$ \\
\hline 2 & SNP & LSC/rps 16-intron & CNS & 5974 & A & $\mathrm{C}$ & A \\
\hline 3 & SNP & LSC/rps16-trnQ & $\mathrm{CNS}$ & 6982 & $\mathrm{~T}$ & A & $\mathrm{T}$ \\
\hline 4 & SNP & LSC/trnQ-psbK & $\mathrm{CNS}$ & 7609 & A & $\mathrm{C}$ & A \\
\hline 5 & InDel & $\mathrm{LSC} / \operatorname{trn} S-\operatorname{trn} G$ & $\mathrm{CNS}$ & $8635-8636$ & - & $\mathrm{A}$ & $\mathrm{A}$ \\
\hline 6 & SNP & $\mathrm{LSC} / \operatorname{trn} G$-intron & $\mathrm{CNS}$ & 9309 & $\mathrm{G}$ & $\mathrm{T}$ & G \\
\hline 7 & SNP & $\mathrm{LSC} / \operatorname{trn} G-\operatorname{trn} R$ & $\mathrm{CNS}$ & 9834 & $\mathrm{~T}$ & $\mathrm{~T}$ & A \\
\hline 8 & InDel & $\mathrm{LSC} / r p s 2-r p o C 2$ & $\mathrm{CNS}$ & $15742-15743$ & - & A & - \\
\hline 9 & SNP & $\mathrm{LSC} / r p o B-\operatorname{trn} C$ & $\mathrm{CNS}$ & 26855 & $\mathrm{C}$ & $\mathrm{C}$ & $\mathrm{A}$ \\
\hline 10 & InDel & $\mathrm{LSC} / r p o B-\operatorname{trn} C$ & $\mathrm{CNS}$ & 26942 & $\mathrm{~A}$ & - & - \\
\hline 11 & SNP & $\mathrm{LSC} / t r n C-p e t N$ & $\mathrm{CNS}$ & 27715 & G & $\mathrm{T}$ & G \\
\hline 12 & SNP & $\mathrm{LSC} / \operatorname{trn} E-\operatorname{trn} T$ & CNS & 31611 & $\mathrm{~A}$ & $\mathrm{~T}$ & A \\
\hline 13 & SNP & $\mathrm{LSC} / t r n T-p s b D$ & $\mathrm{CNS}$ & 32314 & $\mathrm{~A}$ & $\mathrm{~T}$ & A \\
\hline 14 & SNP & $\mathrm{LSC} / t r n T-p s b D$ & $\mathrm{CNS}$ & 32709 & $\mathrm{~T}$ & A & $\mathrm{A}$ \\
\hline 15 & SNP & $\mathrm{LSC} / t r n T-p s b D$ & $\mathrm{CNS}$ & 33453 & $\mathrm{C}$ & $\mathrm{A}$ & $\mathrm{C}$ \\
\hline \multirow[t]{2}{*}{16} & InDel & $\mathrm{LSC} / \operatorname{trn} G$-trnfM & $\mathrm{CNS}$ & $37465-37466$ & - & - & CCCCAAGAAAAAAAGG \\
\hline & & & & & & & TAATTAATTATTCTTT \\
\hline 17 & InDel & $\mathrm{LSC} / y c f 3-\operatorname{trn} S$ & CNS & 45458 & $\mathrm{~T}$ & - & $\mathrm{T}$ \\
\hline 18 & InDel & $\mathrm{LSC} / y c f 3-\operatorname{trn} S$ & $\mathrm{CNS}$ & $46152-46153$ & - & - & $\mathrm{T}$ \\
\hline 19 & SNP & $\mathrm{LSC} / \operatorname{trn} T$-trnL & CNS & 47869 & $\mathrm{C}$ & $\mathrm{A}$ & $\mathrm{C}$ \\
\hline 20 & SNP & $\mathrm{LSC} / t r n T-t r n L$ & $\mathrm{CNS}$ & 48096 & $\mathrm{~A}$ & $\mathrm{C}$ & $\mathrm{A}$ \\
\hline 21 & SNP & LSC/trnT-trnL & $\mathrm{CNS}$ & 48097 & G & $\mathrm{T}$ & $\mathrm{T}$ \\
\hline 22 & SNP & $\mathrm{LSC} / \operatorname{trn} L-\operatorname{trn} F$ & $\mathrm{CNS}$ & 49580 & $\mathrm{~T}$ & $\mathrm{C}$ & $\mathrm{T}$ \\
\hline 23 & SNP & LSC/trnF-ndhJ & CNS & $50344-50348$ & AAAAG & AAAAG & CTTTT \\
\hline 24 & SNP & $\mathrm{LSC} /$ trn $V$-intron & $\mathrm{CNS}$ & 53230 & $\mathrm{C}$ & A & $\mathrm{C}$ \\
\hline 25 & InDel & $\mathrm{LSC} / a c c D-p s a I$ & $\mathrm{CNS}$ & 59997-60008 & AATTTATTTTTA & - & AATTTATTTTTA \\
\hline 26 & InDel & $\mathrm{LSC} / p s a I-y c f 4$ & CNS & 60623 & $\mathrm{~T}$ & - & - \\
\hline 27 & InDel & $\mathrm{LSC} / p e t A-p s b J$ & CNS & 64224 & G & - & G \\
\hline
\end{tabular}




\begin{tabular}{|c|c|c|c|c|c|c|}
\hline 28 & InDel & LSC/ petA-psbJ & $\mathrm{CNS}$ & $64355-64356$ & - & $\mathrm{T}$ \\
\hline 29 & InDel & $\mathrm{LSC} / p s b E-p e t L$ & CNS & 66485 & A & - \\
\hline 30 & SNP & $\mathrm{LSC} / t r n P-p s a J$ & CNS & 67723 & $\mathrm{C}$ & $\mathrm{C}$ \\
\hline 31 & InDel & $\mathrm{LSC} / t r n P-p s a J$ & $\mathrm{CNS}$ & 67834-67835 & - & TAGTAA \\
\hline 32 & SNP & LSC/psaJ-rpl33 & $\mathrm{CNS}$ & 68408 & A & A \\
\hline 33 & InDel & LSC/rps18-rpl20 & $\mathrm{CNS}$ & 69490 & $\mathrm{~A}$ & - \\
\hline 34 & InDel & LSC/ rps18-rpl20 & $\mathrm{CNS}$ & 69491 & A & - \\
\hline 35 & SNP & LSC/rpl20-rps 12 & CNS & 70254 & $\mathrm{~A}$ & G \\
\hline 36 & SNP & LSC/rpl20-rps 12 & $\mathrm{CNS}$ & 70519 & A & A \\
\hline 37 & InDel & $\mathrm{LSC} / r p s 12-c l p P$ & CNS & 70966-70967 & - & $\mathrm{T}$ \\
\hline 38 & SNP & $\mathrm{LSC} / r p s 12-c l p P$ & $\mathrm{CNS}$ & 70999 & $\mathrm{G}$ & G \\
\hline 39 & InDel & LSC/clpP-intron & $\mathrm{CNS}$ & 71668-71669 & - & $\mathrm{T}$ \\
\hline 40 & SNP & LSC/clpP-intron & $\mathrm{CNS}$ & 71681 & $\mathrm{C}$ & A \\
\hline 41 & SNP & LSC/clpP-intron & $\mathrm{CNS}$ & 72808 & $\mathrm{~T}$ & $\mathrm{C}$ \\
\hline 42 & InDel & LSC/psbT-psbN & $\mathrm{CNS}$ & $75456-75457$ & - & САТТАТСТСААТТG \\
\hline & & & & & & AAAGT \\
\hline 43 & SNP & LSC/petD-intron & CNS & 78077 & G & A \\
\hline 44 & SNP & LSC/rpl36-rps 8 & $\mathrm{CNS}$ & 80856 & $\mathrm{C}$ & G \\
\hline 45 & InDel & LSC/rpl14-rpl16 & CNS & 82300 & $\mathrm{~T}$ & - \\
\hline 46 & SNP & LSC/rpl16-intron & $\mathrm{CNS}$ & 82928 & G & $\mathrm{T}$ \\
\hline 47 & SNP & LSC/rpll6-intron & $\mathrm{CNS}$ & 83676 & $\mathrm{~T}$ & $\mathrm{~T}$ \\
\hline 48 & SNP & $\mathrm{IR} / r p s 12-t r n V$ & CNS & 100249 & $\mathrm{C}$ & A \\
\hline 49 & SNP & $\mathrm{IR} / r r n 5-t r n R$ & $\mathrm{CNS}$ & 109248 & G & $\mathrm{T}$ \\
\hline 50 & SNP & $\begin{array}{l}\mathrm{IR} / \mathrm{trnN} \text { - } \\
y c f 1 \text { (short) }\end{array}$ & CNS & 110162 & A & G \\
\hline 51 & SNP & $\mathrm{SSC} / n d h F-r p l 32$ & $\mathrm{CNS}$ & 113838 & $\mathrm{~T}$ & A \\
\hline 52 & SNP & SSC/rpl32-trnL & CNS & 114675 & $\mathrm{~T}$ & $\mathrm{~T}$ \\
\hline 53 & SNP & $\mathrm{SSC} / n d h D-p s a C$ & $\mathrm{CNS}$ & 118166 & $\mathrm{C}$ & $\mathrm{A}$ \\
\hline 54 & InDel & $\mathrm{SSC} / p s a C-n d h E$ & CNS & $118599-118600$ & - & A \\
\hline
\end{tabular}




\begin{tabular}{|c|c|c|c|c|c|c|c|}
\hline 55 & SNP & $\mathrm{SSC} / n d h A$-intron & CNS & 122406 & $\mathrm{C}$ & A & $\mathrm{C}$ \\
\hline 56 & SNP & $\mathrm{LSC} / a c c D$ & gene & 58891 & $\mathrm{C}$ & $\mathrm{T}$ & $\mathrm{C}$ \\
\hline 57 & SNP & $\mathrm{SSC} / n d h F$ & gene & 113349 & A & G & A \\
\hline 58 & SNP & $\mathrm{SSC} / n d h H$ & gene & 123504 & $\mathrm{~T}$ & $\mathrm{C}$ & $\mathrm{T}$ \\
\hline 59 & SNP & $\mathrm{LSC} / p e t B$ & gene & 77457 & G & G & $\mathrm{T}$ \\
\hline 60 & SNP & $\mathrm{LSC} / p s b A$ & gene & 676 & A & A & G \\
\hline 61 & SNP & $\mathrm{LSC} / r p o B$ & gene & 25334 & $\mathrm{~T}$ & G & G \\
\hline 62 & SNP & $\mathrm{LSC} / r p s 8$ & gene & 81522 & $\mathrm{~T}$ & $\mathrm{~T}$ & $\mathrm{C}$ \\
\hline 63 & SNP & $\mathrm{SSC} / y c f 1$ & gene & 125275 & G & $\mathrm{T}$ & G \\
\hline 64 & SNP & $\mathrm{SSC} / y c f 1$ & gene & 128610 & G & $\mathrm{C}$ & G \\
\hline 65 & SNP & $\mathrm{SSC} / y c f 1$ & gene & 129102 & G & G & $\mathrm{T}$ \\
\hline 66 & SNP & $\mathrm{SSC} / y c f 1$ & gene & 129303 & $\mathrm{C}$ & $\mathrm{A}$ & $\mathrm{C}$ \\
\hline 67 & SNP & LSC/ycft & gene & 61151 & G & A & A \\
\hline
\end{tabular}

1 Notes.

$2 \quad{ }^{\mathrm{a}} \mathrm{CNS}=$ Non-coding sequences which containing intergenic spacer region and introns.

3 'Nucleotide position is referenced to the chloroplast genome of $F$. $\times$ ananassa 'Benihoppe'. 